OPEN ACCESS

Edited by:

Ali H. Eid,

American University of Beirut,

Lebanon

Reviewed by:

Alessandra Bitto,

University of Messina, Italy

Alicja Węgrzyn,

Polish Academy of Sciences,

Poland

Matthew Donovan Fountain,

Michigan State University,

United States

*Correspondence:

Anupam Bishayee abishayee@lecom.edu; abishayee@gmail.com

tThese authors have contributed equally to this work and share first authorship

Specialty section:

This article was submitted to Translational Pharmacology,

a section of the journal

Frontiers in Pharmacology

Received: 05 August 2019

Accepted: 18 October 2019

Published: 06 December 2019

Citation:

Tuli HS, Tuorkey MJ, Thakral F, Sak K, Kumar M, Sharma AK, Sharma U, Jain A, Aggarwal $V$ and Bishayee A (2019) Molecular Mechanisms of Action of Genistein in Cancer:

Recent Advances.

Front. Pharmacol. 10:1336. doi: 10.3389/fphar.2019.01336

\section{Molecular Mechanisms of Action of Genistein in Cancer: Recent Advances}

\author{
Hardeep Singh Tuli't, Muobarak Jaber Tuorkey ${ }^{2 \dagger}$, Falak Thakral', Katrin Sak ${ }^{3}$, \\ Manoj Kumar ${ }^{4}$, Anil Kumar Sharma1, Uttam Sharma ${ }^{5}$, Aklank Jain ${ }^{5}$, Vaishali Aggarwal ${ }^{6}$ \\ and Anupam Bishayee ${ }^{7 *}$
}

${ }^{1}$ Department of Biotechnology, Maharishi Markandeshwar (Deemed to be University), Mullana-Ambala, India, ${ }^{2}$ Division of Physiology, Zoology Department, Faculty of Science, Damanhour University, Damanhour, Egypt, ${ }^{3}$ NGO Praeventio, Tartu, Estonia, ${ }^{4}$ Department of Chemistry, Maharishi Markandeshwar University, Sadopur, India, ${ }^{5}$ Department of Animal Sciences, Central University of Punjab, Bathinda, India, ${ }^{6}$ Department of Histopathology, Post Graduate Institute of Medical Education and Research, Chandigarh, India, ${ }^{7}$ Lake Erie College of Osteopathic Medicine, Bradenton, FL, United States

Background: Genistein is one among the several other known isoflavones that is found in different soybeans and soy products. The chemical name of genistein is 4',5,7-trihydroxyisoflavone. Genistein has drawn attention of scientific community because of its potential beneficial effects on human grave diseases, such as cancer. Mechanistic insight of genistein reveals its potential for apoptotic induction, cell cycle arrest, as well as antiangiogenic, antimetastatic, and anti-inflammatory effects.

Objective: The purpose of this review is to unravel and analyze various molecular mechanisms of genistein in diverse cancer models.

Data sources: English language literature was searched using various databases, such as PubMed, ScienceDirect, EBOSCOhost, Scopus, Web of Science, and Cochrane Library. Key words used in various combinations included genistein, cancer, anticancer, molecular mechanisms prevention, treatment, in vivo, in vitro, and clinical studies.

Study selection: Study selection was carried out strictly in accordance with the statement of Preferred Reporting Items for Systematic Reviews and Meta-analyses.

Data extraction: Four authors independently carried out the extraction of articles.

Data synthesis: One hundred one papers were found suitable for use in this review.

Conclusion: This review covers various molecular interactions of genistein with various cellular targets in cancer models. It will help the scientific community understand genistein and cancer biology and will provoke them to design novel therapeutic strategies.

Keywords: genistein, cancer, proliferation, apoptosis, metastasis, in vitro, in vivo

\section{INTRODUCTION}

Genistein [5,7-dihyroxy-3-(-4-hydroxyphenyl)-4H-1-benzopyran-4-one] is a major isoflavone in soy and soy-based food products that are regularly consumed by people in Asian countries (Ronis, 2016). Indeed, median daily intake of isoflavones among adults in Japan and China is about 25-50 mg which is several-folds higher than the consumption of these compounds by women in the western countries 
(less than $3 \mathrm{mg}$ ) (Sak, 2017a). Several epidemiological studies have suggested a lower incidence of certain cancer types, such as breast and prostate cancer, in Asian countries as compared to the western world. Therefore, recent interest has been focused on the possible contribution of high dietary consumption of isoflavones for prevention and suppression of tumorigenesis (Sak, 2017b). In the past few decades, numerous studies have been published about the potential anticancer role of genistein both in cell cultures as well as animal models (Spagnuolo et al., 2015; Kim et al., 2014). This natural isoflavone can exhibit a wide range of important properties, including antioxidant, anti-inflammatory, antiangiogenic, proapoptotic, and antiproliferative activities, all of which confer chemopreventive, and chemotherapeutic potential of genistein (Kim et al., 2014; Ganai and Farooqi, 2015; Uifalean et al., 2015).

Despite extensive studies, cancer has remained one of the gravest diseases and biggest challenges for human health all over the world, being a leading cause of death in the industrialized countries. For more than half a century, various chemotherapeutic drugs have been developed and used for treatment of tumors; however, there are still no curative options currently available in clinical settings (Crawford, 2013). Therefore, natural agents with strong anticancer activities could be considered as novel potential lead compounds for the development of more efficient and selective anti-neoplastic drugs (Bishayee, 2012; Shanmugam et al., 2016). Genistein may be one of such lead compounds; it is safe and its anticancer efficiency has already been proven in numerous preclinical investigations. This soy isoflavone can affect various molecular targets and modulate various signaling pathways, thereby influencing the ultimate response of cancer cells (Spagnuolo et al., 2015; Russo et al., 2016; Ardito et al., 2018; Chae et al., 2019). However, besides the anticancer effects, contradictory action has also been described for genistein by promoting growth of malignant cells (Russo et al., 2016), making studies with this molecule a scientific challenge. Therefore, in this article, molecular mechanisms of genistein in malignant cells are unraveled and analyzed.

\section{METHODOLOGY FOR LITERATURE SEARCH}

Various authentic and reliable databases, such as PubMed, EBOSCOhost, ScienceDirect, Scopus, Web of Science, and Cochrane Library, were used to search and collect literature. The Preferred Reporting Items for Systematic Reviews and Meta-Analysis (PRISMA) criteria (Liberati et al., 2009) has been followed. Relevant full-length articles published in peerreviewed journals until June, 2019 were included. Conference abstracts, book chapters, and unpublished results were not included. Only English language articles were included in this review. Major keywords used in various combinations included: genistein, cancer, anticancer, molecular mechanisms prevention, treatment, in vivo, in vitro, and clinical studies. The bibliography of the primary literature was also studied to collect additional relevant articles.

\section{CHEMISTRY OF GENISTEIN}

Genistein belongs to isoflavone family and is obtained from soy products, such as soybeans. It is very well-known plant secondary metabolite that consists of the 3-phenylchromen-4one nucleus made up of two aromatic rings (A and B) (Figure 1).

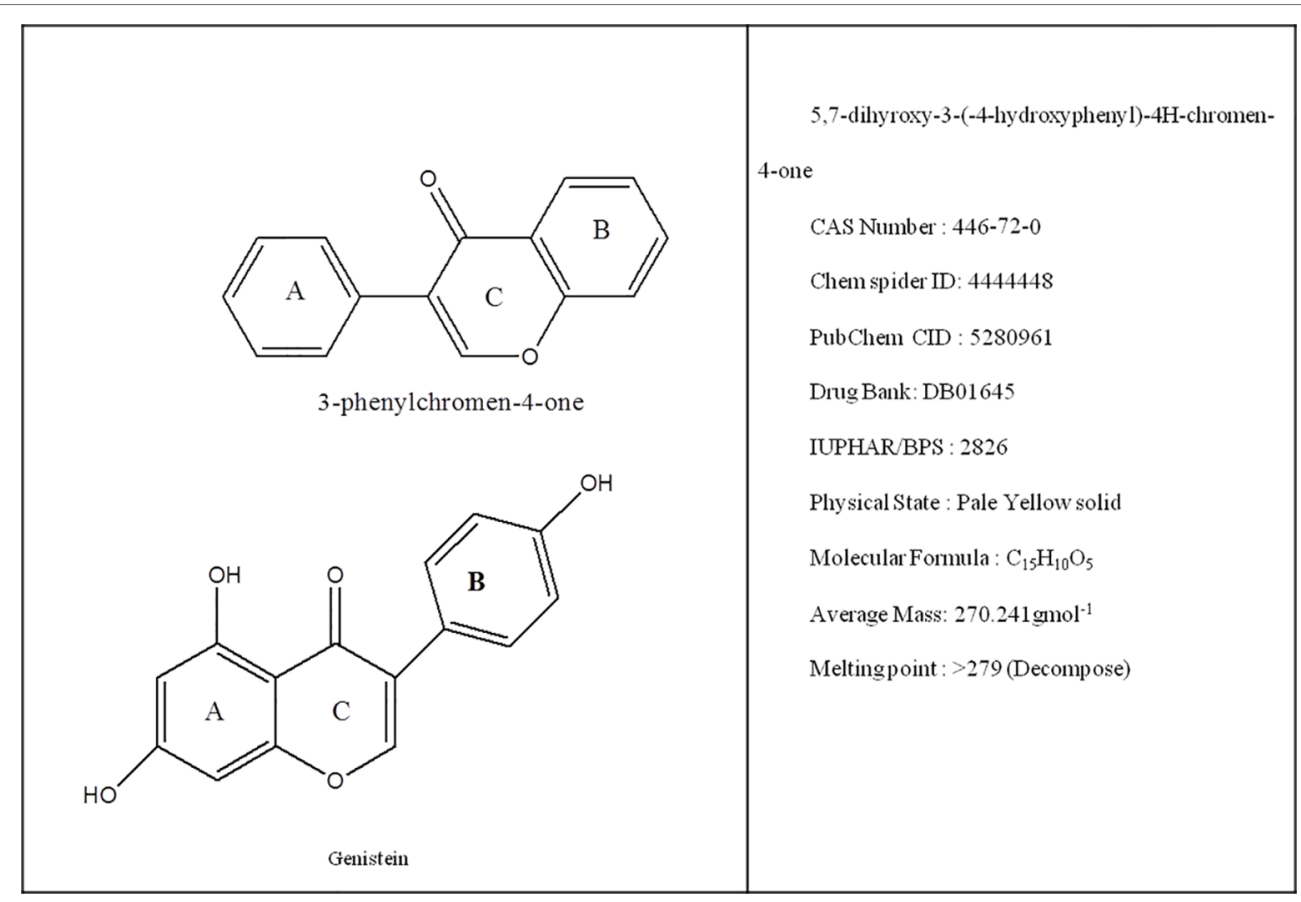

FIGURE 1 | Representation of basic nucleus of isoflavones along with chemical and physical properties of genistein. 
Further, these rings are linked to another carbon pyran ring (C) (Figure 1). Other functional group in its basic carbon skeleton are $\mathrm{C}_{2}-\mathrm{C}_{3}$ double bond, an oxo group at $\mathrm{C} 4$ position of ring $\mathrm{C}$. Additionally, there are three hydroxyl groups at $\mathrm{C} 5$, $\mathrm{C} 7$, and $\mathrm{C}^{\prime}$ positions of ring $\mathrm{A}$ and $\mathrm{B}$, respectively (Figure 1). Genistein was first isolated in 1899 from a species of flowering plant Genista tinctoria (Dyer's broom) of family Fabaceae (Perkin and Newbury, 1899). Following the initial discovery, it has been found in many plants, such as lupin, fava beans, soybeans, and kudzu. Genistein was successfully synthesized first time in 1928 (Baker and Robinson, 1928).

Genistein is synthesized by treatment of trihydroxybenzoin, which, in turn, is obtained via acylation of phloroglucinol, with substituted phenyl acetonitrile using $\mathrm{HCl}$ and anhydrous $\mathrm{ZnCl}_{2}$ in dry ether as catalyst (Figure 2) (Hamza Sherif and Gebreyohannes, 2018). In another approach, genistein has been synthesized from 2,4,6-trihydroxyphenyl) ethanone via protection of two hydroxyl substituent in triol as methoxymethyl ester so as to overcome the problem of reaction of dimethoxy methyl dimethylamine with phenol (Figure 3) (Denis et al., 2010).

The derivatives of genistein can also be achieved by Ferrier rearrangements of 3,4-di-O-acetyl-L-rhamnal with 3-bromopropanol to 2,3-unsaturated bromoalkylglycosides followed by epoxidation with meta-chloroperoxybenzoic acid and subsequently connected with genistein (Goj et al., 2012). Additionally, genistein derivatives are also derived through novel chemical glycosylation and glycoconjugation process (Szeja et al., 2017).

\section{MOLECULAR MECHANISMS OF ACTION OF GENISTEIN}

The molecular mechanism of action of genistein as a chemotherapeutic agent has been extensively studied in different types of cancers. Genistein modulates various steps of cell cycle, apoptosis, angiogenesis, and metastasis. The main molecular targets of genistein include caspases, B-cell lymphoma 2 (Bcl$2), \mathrm{Bcl}-2$-associated $\mathrm{X}$ protein (Bax), nuclear factor- $\kappa \mathrm{B}(\mathrm{NF}-\kappa \mathrm{B})$, inhibitor of NF- $\kappa \mathrm{B}$, phosphoinositide 3-kinase/Akt (PI3K/Akt), extracellular signal-regulated kinase $1 / 2$ (ERK 1/2), mitogenactivated protein kinase (MAPK), and Wingless and integration $1 / \beta$-catenin (Wnt $/ \beta$-catenin) signaling pathway. Besides the transcription factors, genistein-induced endoplasmic reticulum (ER) stress and its downstream targets are also reported to induce apoptosis in cancer. Interestingly, peroxisome proliferatoractivated receptors (PPARs) have also surfaced as potential therapeutic targets of interest for modulating tumor growth, and genistein has been documented to induce apoptosis in tumor cells via targeting PPAR $\gamma$ signaling cascade. The underlying molecular mechanism of action of genistein in apoptosis induction, cell cycle arrest, anti-inflammatory potential along with inhibition of angiogenesis, and metastasis are discussed in detail in the following sections and summarized in Table $\mathbf{1 .}$

\section{Induction of Apoptosis}

Apoptosis, a programmed cell death, is mainly characterized by a series of distinct changes in cell morphology, such as blebbing, loss

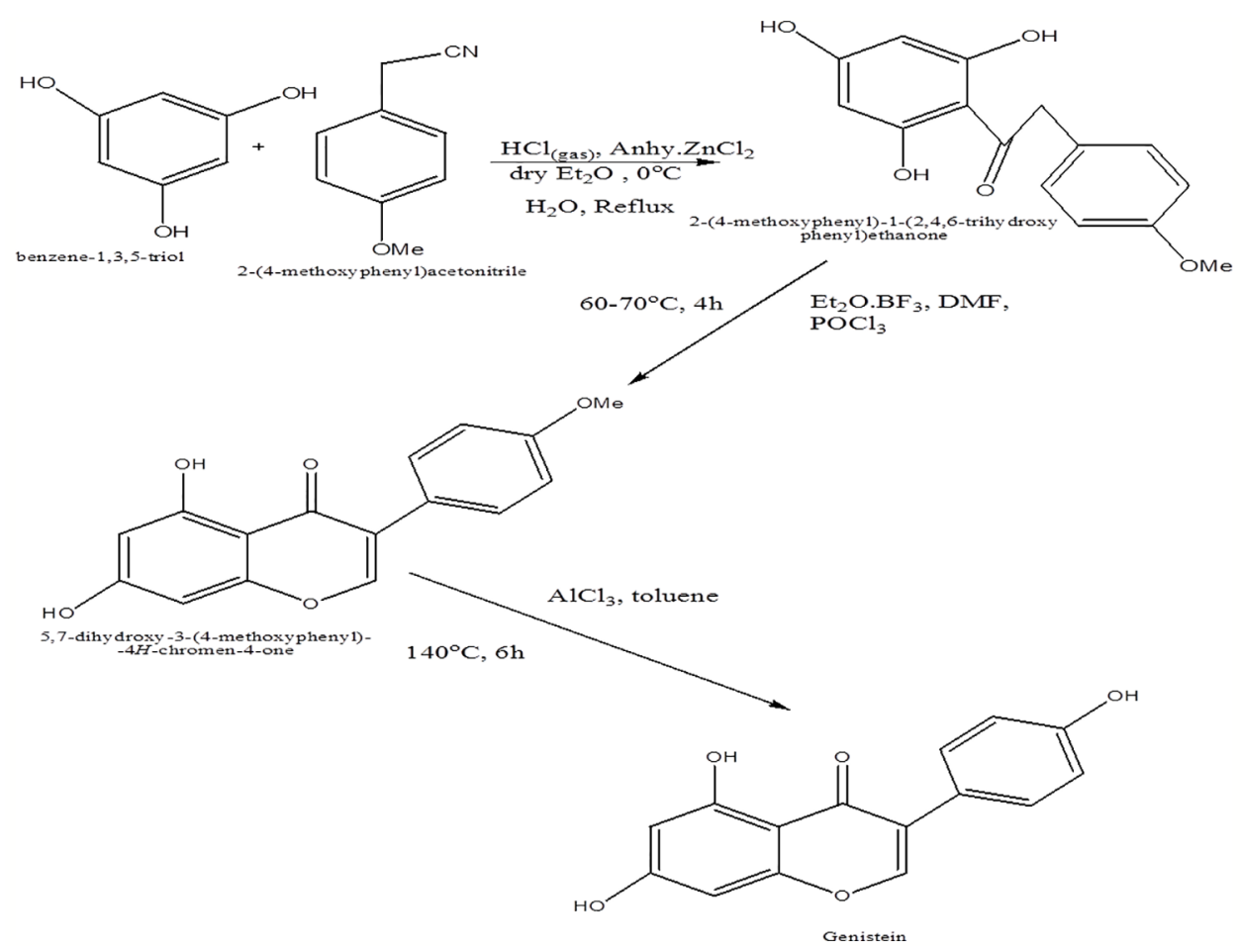

FIGURE 2 | Synthesis route of genistein via trihydroxybenzoin. 


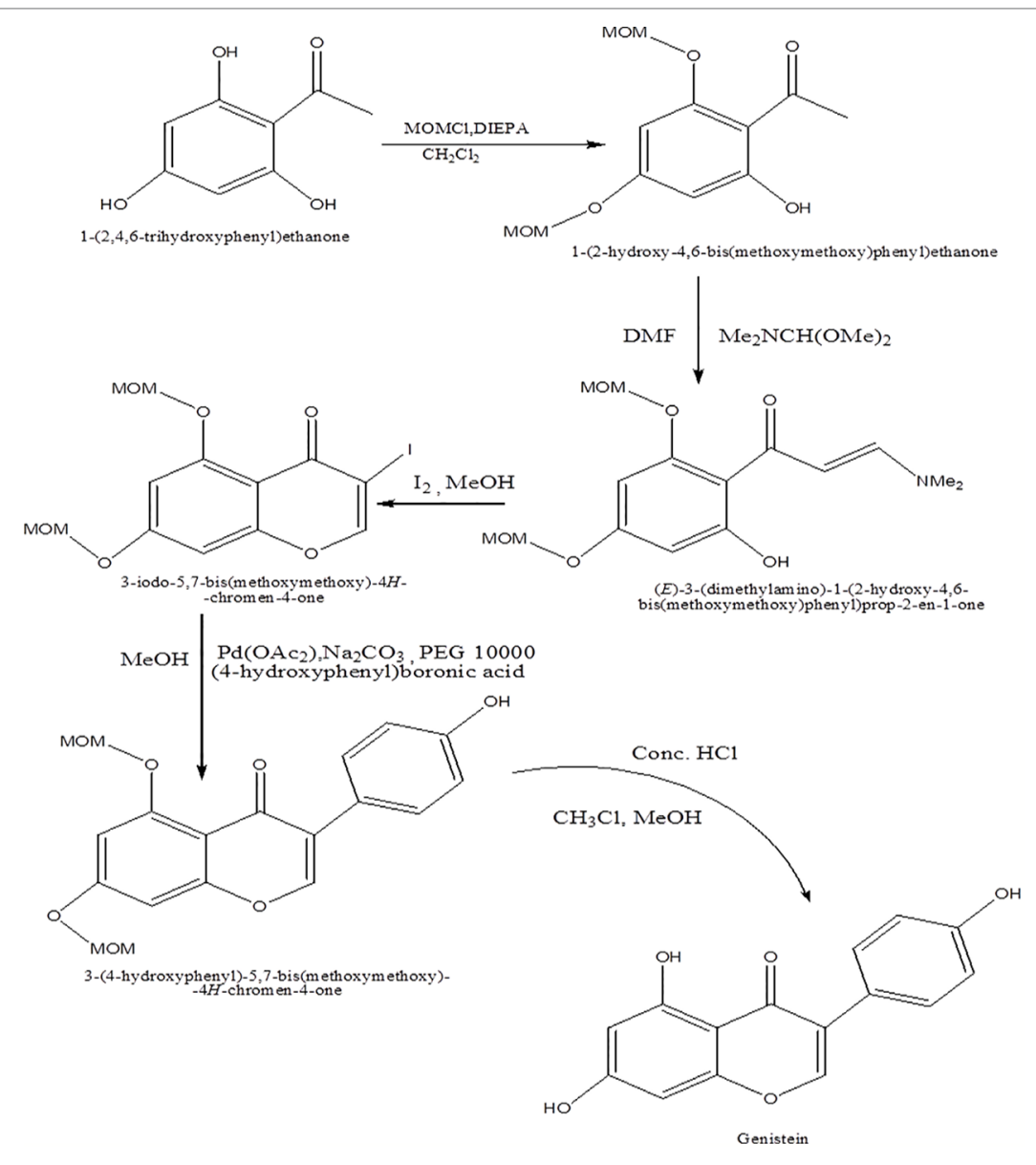

FIGURE 3 | Synthesis of genistein from 1-(2,4,6-trihydroxyphenyl)ethanone.

of cell attachment, cytoplasmic contraction, DNA fragmentation, and other biochemical changes, including the activation of caspases through extrinsic and/or intrinsic mitochondrial pathways. Past research has demonstrated the role of genistein in the induction of apoptosis through regulation of expression of various proteins (Figure 4). Genistein was able to induce apoptosis in human cervical cancer cells (HeLa cells) by enhancing the activities of each of caspase- 9 and caspase-3, and/or both (Dhandayuthapani et al., 2013). Additionally, genistein could trigger apoptotic cell death by inhibiting NF- $\mathrm{BB}$ pathway and modulating the levels of antiapoptotic protein $\mathrm{Bcl}-2$ and proapoptotic protein (Bax) in LoVo and HT-29 colon cancer cell lines (Luo et al., 2014). Genistein also promoted apoptosis in HT29 colon cancer cells by modulating caspase- 3 and p38 MAPK signaling pathway (Shafiee et al., 2016).

In another context, genistein-mediated apoptosis via induction of ER stress was recently proposed as a potential mechanism for the induction of apoptosis in human cervical cancer cells via upregulating the expression of glucose-regulated protein 78 (GRP78) and CCAAT/enhancer-binding protein homologous protein (Yang et al., 2016). Recently, a study using Hepa1-6 hepatocellular carcinoma cells has also confirmed the concentration-dependent apoptotic effect of genistein (Sanaei et al., 2018). In this regard, the release of cytochrome c (cyt c) and activation of the apoptotic protease activator factor 1 from the mitochondria are the marginal factors in the induction of apoptosis. One of the possible mechanisms is that genistein induced the activity of the $\mathrm{Ca}^{2+}$-dependent enzyme, namely calpain, which cleaves cytosolic Bax and Bid which, in turn, truncated apoptosisinducing factor and cyt c release (Das et al., 2010). The other possible mechanism is that genistein increased the expression of ER stress-associated proteins, such as inositol-requiring enzyme 1a, calpain 1, $78 \mathrm{kDa}$ GRP78, growth arrest, and DNA damageinducible gene 153, caspase-7, and caspase-4. The upregulation of full form of GRP78 was involved in the ER stress (Hsiao et al., 2019). The induction of the latter upregulated the activity of protein kinase R-like ER kinase, which, in turn, activates the transcription factor CCAAT/enhancer-binding protein homologous protein to induce apoptosis (Xia et al., 2019). It has also been postulated that genistein enhanced the phosphorylation and activation of $\mathrm{p} 53$, while decreased the ratio of $\mathrm{Bcl}-2 / \mathrm{Bax}$ and $\mathrm{Bcl}-\mathrm{xL} / \mathrm{Bax}$ and the level of phosphorylated Akt (also known as protein kinase B), which result in cells undergoing apoptosis (Ouyang et al., 2009). Genistein-mediated activated protein kinase (AMPK) upregulation increased apoptosis of hepatocytes, in hepatocellular carcinoma (HCC) through energy-dependent caspase pathway (Lee et al., 2019). In Hep3B cells, genistein activated AMPK, 
TABLE 1 | Anticancer molecular mechanism of genistein.

\begin{tabular}{|c|c|c|c|}
\hline Effect & Mechanism & Cancer model & Reference \\
\hline \multirow[t]{7}{*}{ Apoptosis-evasion } & $\begin{array}{l}\text { ER-stress and mitochondrial involvement, } \uparrow A T F-6 \alpha, \uparrow G R P-78 \text {, } \\
\uparrow B a x, \uparrow B a d, \uparrow B a k\end{array}$ & HL-60 & Hsiao et al. (2019) \\
\hline & $\downarrow P K L 1$ & & Chae et al. (2019 \\
\hline & $\downarrow M M P, \uparrow R O S$ & Mia-PaCa2 and PANC-1 & Bi et al. (2018) \\
\hline & $\uparrow$ Capase-3 & HT29 & Shafiee et al. (2016) \\
\hline & $\downarrow M D M 2, \downarrow X I A P, \downarrow$ caspase-3 & HeLa & Xie et al. (2013) \\
\hline & $\downarrow \mathrm{CIP} 2 \mathrm{~A}$ mRNA with modulation of E2F1 & MCF-7-C3 and T47D & Zhao et al. (2016) \\
\hline & 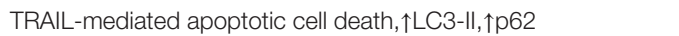 & A549 & Nazim et al. (2015) \\
\hline \multirow[t]{6}{*}{ Cell cycle arrest } & $\mathrm{G}_{2} / \mathrm{M}$ arrest & HL-60 & Hsiao et al. (2019) \\
\hline & $\mathrm{G}_{0} / \mathrm{G}_{1}$ arrest by cell cycle transition & MCF-7/ER $\beta 1$ & Jiang et al. (2018) \\
\hline & $\mathrm{G}_{0} / \mathrm{G}_{1}$ arreast & Mia-PaCa2 and PANC-1 & Bi et al. (2018) \\
\hline & Mitotic arrest, $\downarrow$ PIK1 & TP53-mutated A460 cancer cells & Shin et al. (2017) \\
\hline & $\mathrm{G}_{2} / \mathrm{M}$ arrest & HCT116 & Mizushina et al. (2013) \\
\hline & $\begin{array}{l}\mathrm{G}_{2} / \mathrm{M} \text { arrest by telomere shortening via suppression of } \mathrm{TR} \text { and } \\
\text { TERT mRNA }\end{array}$ & $\begin{array}{l}\text { Glioblastoma multiforme and } \\
\text { medulloblastoma cells }\end{array}$ & Khaw et al. (2012) \\
\hline \multirow[t]{2}{*}{ Antimetastastic } & $\downarrow$ MMP2 & HT29 & Shafiee et al. (2016) \\
\hline & $\downarrow$ DMBA-induced metastatic transition & Mouse model & Banerjee et al. (2008) \\
\hline Anti-inflammatory & Decreases TNF- $\alpha$-induced fractalkine expression & THP-1 & Sung et al. (2010) \\
\hline \multirow[t]{9}{*}{ Antiproliferative } & $\uparrow p-E R K, \uparrow p C R E B, \uparrow B D N F, \downarrow A C h E$ & Mouse model & Lu et al. (2018) \\
\hline & $\begin{array}{l}\downarrow \mathrm{mTOR}, \downarrow \mathrm{p} 70 \mathrm{~S} 6 \mathrm{~K} 1, \downarrow 4 \mathrm{E}-\mathrm{BP} 1, \downarrow \mathrm{NF}-\mathrm{kB}, \downarrow \mathrm{Bcl}-2, \uparrow \mathrm{Nr} 2, \uparrow \mathrm{HO}-1, \\
\uparrow \mathrm{Bax}\end{array}$ & Hen model & Sahin et al. (2019) \\
\hline & $\downarrow D N M T s, \downarrow H D A C s$ & HeLa cells & Sundaram et al. (2018) \\
\hline & \DNA methylation, $\uparrow A T M, \uparrow A P C, \uparrow P T E N, \uparrow S E R P I N B 5$ & MCF-7 and MDA-MB-231 & Xie et al. (2014) \\
\hline & $\downarrow$ Crosstalk between ER $\alpha$ and IGF-IR pathway, $\uparrow$ BPA $\uparrow$ estrogen & BG-1 & Hwang et al. (2013) \\
\hline & $\downarrow$ Topoisomerase ॥ & HCT116 & Mizushina et al. (2013) \\
\hline & $\begin{array}{l}\uparrow E R \alpha \text { expression, } \uparrow \text { TAM-dependent antiestrogen therapeutic } \\
\text { sensitivity }\end{array}$ & $\begin{array}{l}\text { ER } \alpha \text {-positive MCF-7 and ER } \alpha \text {-negative } \\
\text { MDA-MB-231 and MDA-MB-157 cells }\end{array}$ & Li et al. (2013) \\
\hline & $\downarrow M M P-2, \downarrow$ VEGF & Glioma cells & Yazdani et al. (2016) \\
\hline & $\begin{array}{l}\uparrow p 53, D K K 1, \downarrow H D A C 4 / 5 / 7, \downarrow D V L, \downarrow B A X, \downarrow \text { survivin, } \downarrow \text { phospho } \\
\text { MEK }\end{array}$ & SK-UT-1, MES-SA-Dx5, MES-SA & Yeh et al. (2015) \\
\hline
\end{tabular}

which promoted apoptosis accompanied by downregulation of the proinflammatory responses and increasing mitochondrial respiration. Genistein has a potent anti-inflammatory effect by decreasing the secretion of interleukin- $1 \beta$ (IL-1 $\beta$ ), IL- 6 , and IL-8 from tumor necrosis factor- $\alpha$ (TNF- $\alpha$ )-stimulated MH7A cells. Furthermore, genistein prevented TNF- $\alpha$-induced NF- $\kappa B$ translocation into nucleus as well as phosphorylation of inhibitor of $\kappa \mathrm{Ba}(\mathrm{I} \kappa \mathrm{B} \alpha)$ and I $\kappa \mathrm{B}$ kinase- $\alpha / \beta$, and also suppressed TNF- $\alpha-$ induced AMPK inhibition (Li et al., 2014), which halted cellular proliferation and their survival. Another possible mechanism for the ability of genistein to mediate apoptosis came from its ability to induce phosphorylation of the ataxia-telangiectasia mutated (ATM) protein family and ATM-related (ATR) and activation of Chk1 and Chk2 checkpoint kinases (Ouyang et al., 2009), which in turn, phosphorylates and inactivates of phosphatases Cdc25C and Cdc25A. The sequence of the latter event includes inactivation of $\mathrm{Cdc} 2$, causing cell arrest in G2/M phase, and mediating apoptosis.

On the other context, genistein can trigger oxidative stressinduced apoptosis via increasing nitric oxide (NO) production and its bioavailability. In support of this hypothesis, it has been reported that genistein enhanced the activity of neuronal nitric oxide synthases (Miao et al., 2018), which promoted NO synthesis from 1-arginine substrate. The latter can interact with superoxide $\left(\mathrm{O}^{2-}\right)$ to form peroxynitrite $\left(\mathrm{OONO}^{-}\right)$and hydroxyl radical $\left(\mathrm{OH}^{-}\right)$that triggers poly(ADP-ribose) polymerase 1 activation, which initiates apoptosis. Lastly but not the least, genistein could mediate apoptosis through inhibiting aerobic glycolysis through downregulation of hypoxia-inducible factor- $1 \alpha$ which inactivates glucose transporter 1 or/and hexokinase 2 (Li et al., 2017).

Further, genistein has also been reported to induce apoptosis via PPAR $\gamma$ pathway which involves PPAR $\gamma, \mathrm{Bcl}-2$, phosphatase and tensin homolog (PTEN), p2 $1^{\text {Waf11/Cip1 }}$, survivin, and cyclin B1. It has been reported that administration of genistein in combination with three polyunsaturated fatty acids, namely docosahexaenoic acid, eicosapentaenoic acid, and arachidonic acid, increased PPAR $\gamma$ expression in MDA-MB-231 human breast cancer cells, and decreased expression of inflammatory molecules cyclooxygenase-2 (COX-2) and prostaglandin $\mathrm{E}_{2}$ $\left(\mathrm{PGE}_{2}\right)$ thereby reverting invasiveness in breast cancer cells (Horia and Watkins, 2007). The growth-inhibitory effect of genistein has also been reported in MG-63 osteosarcoma (OS) cells treated with GW9662, an antagonist of PPAR $\gamma$ (Song et al., 2015). Genistein treatment of OS cells increased PPAR $\gamma$ expression and led to tumor cell apoptosis as a nontoxic activator of PPAR $\gamma$. On the contradictory, genistein in combination with resveratrol was found to downregulate the expression of adipocyte specific proteins, CCAAT/enhancer binding protein- $\alpha$ and $\operatorname{PPAR} \gamma$, thereby inhibiting adipogenesis in 3T3-L1 cells which led to induction of apoptosis and promotion of lipolysis in 3T3L1 adipocytes (Rayalam et al., 2007). This was further supported by another study that documented combination of genistein and daidzein induced downregulation of perilipin-1, Tip-47, and adipose differentiation-related protein family proteins leading to inhibition of lipid droplet accumulation and induction of 


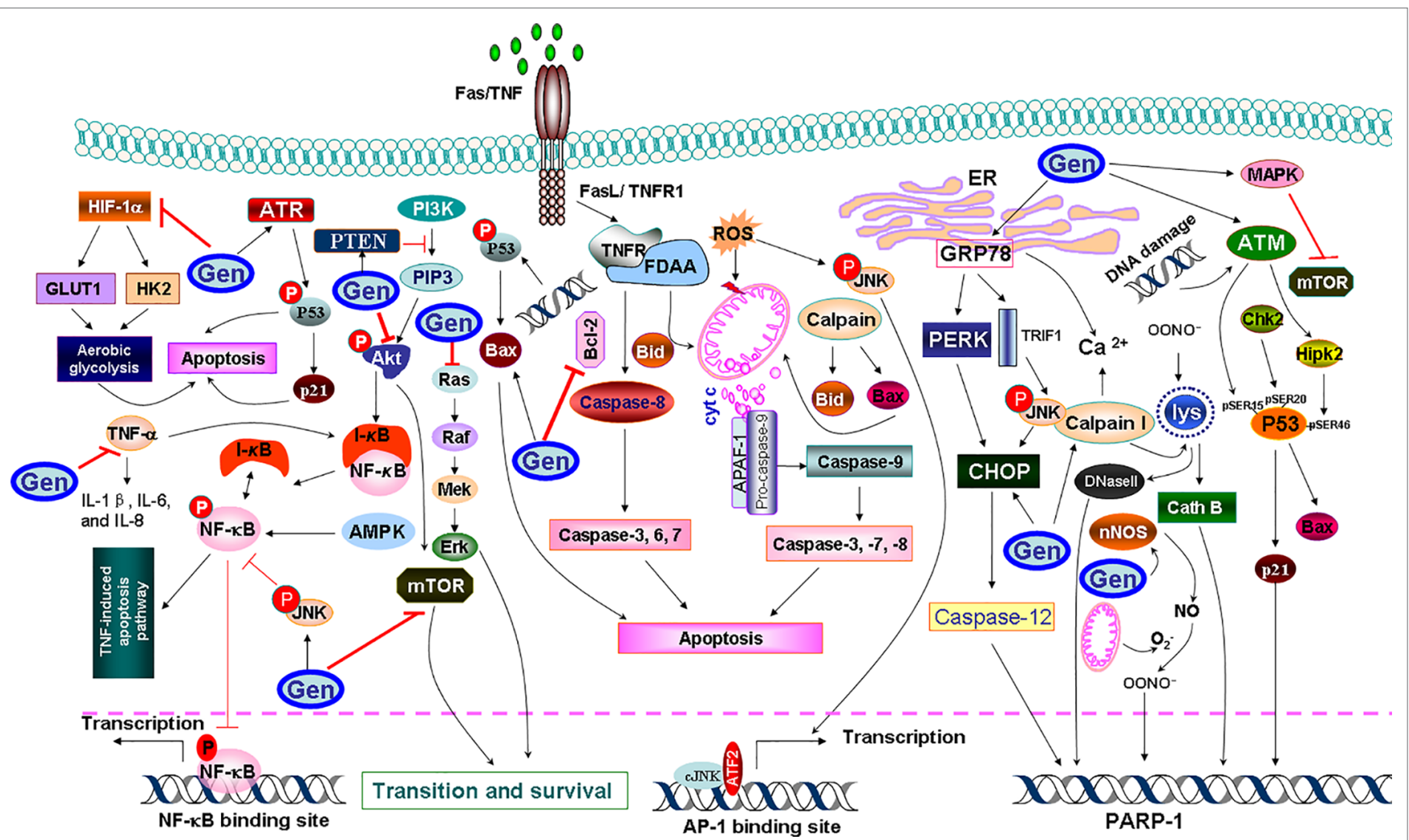

FIGURE 4 | A diagram of mechanistic insight of genistein (Gen) to induce apoptosis in cancer cells. Genistein increases the endoplasmic reticulum (ER) stressassociated protein expressions, such as calpain 1, which cleaves cytosolic Bax and Bid that truncated AIF (tAIF) and cytochrome $c$ (cyt $c$ ) release, along with the activation of the apoptotic protease activator factor 1 (APAF1). Genistein triggers the ER stress through upregulation of glucose-regulated protein 78 (GRP78) expression, which increases the activity of protein kinase R-like ER kinase (PERK), which, in turn activates the transcription factor CCAAT/enhancer-binding protein homologous protein (CHOP) to induce apoptosis. To mediate the extrinsic apoptosis, genistein triggers the combination of a ligand (FasL/TNFR1) and a death receptor (Fas/TNF). Meanwhile, genistein triggers the combination of a ligand (FasL/TNFR1) and a death receptor (Fas/TNF) to mediate the extrinsic pathway. Genistein abolishes tumor necrosis factor- $\alpha$ (TNF- $\alpha$ )-induced nuclear factor- $\mathrm{KB}$ (NF-kB) translocation as well as phosphorylation of IkB kinase- $\alpha / \beta$ and IkB $\alpha$. Genistein also enhances the phosphorylation and activation of ATM/ATR-p53-p21 signaling pathway. Calpain I also permeabilizes lysosomal (lys) membranes, resulting in release of cathepsin B (Cath B) and DNase II. Genistein downregulates hypoxia-inducible factor-1 $\alpha(H I F-1 \alpha)$, therefore inactivating glucose transporter 1 (GLUT1) or/and hexokinase 2 (HK2), which in turn suppresses aerobic glycolysis and mediates apoptosis.

apoptosis in HT-29 colon cancer cells (Liang et al., 2018). In view of the limited scientific evidence supporting regulation of PPAR via genistein, further studies are needed to decipher the precise mechanism of action of genistein via PPAR signaling pathway.

Thus, in view of outlined scientific literature, genistein has been extensively documented to induced cancer cell apoptosis via different signaling cascades from activation of caspases to induction of ER stress, oxidative stress, MAPK, and PPAR $\gamma$ pathway. The in vitro and in vivo results are illustrated to show promising role of genistein in inducing apoptosis in different cancer types. However, further research is still needed to pinpoint the precise intracellular target for maximizing efficacy of genistein as a therapeutic drug.

\section{Cell Cycle Arrest}

The cell cycle is the series of events that take place in a cell, leading to its division and duplication to produce two daughter cells. Genistein regulates the cell growth and cell cycle progression by modulating the expression of cell cycle-regulatory proteins (Figure 5). For instance, genistein inhibited the growth of human gastric carcinoma (HGC-27) cells by arresting the cell cycle succession at $\mathrm{G}_{2}$-M (Matsukawa et al., 1993). Similarly, in galectin-3-transfected human breast epithelial (BT549) cell line, it has been reported that genistein mediated $\mathrm{G}_{2} / \mathrm{M}$ cell cycle arrest via upregulation of the expression of $\mathrm{p} 21^{\text {Waf11/Cip1 }}$ (Lin et al., 2000). Using genistein-treated nonneoplastic human mammary epithelial (MCF-10F) cells, Frey et al. (2001) reported the downregulation of Cdc25C and upregulation of $\mathrm{p} 21^{\mathrm{WAF} / \mathrm{CIP} 1}$ expression. Similarly, genistein-treated neuroblastoma (B35) cells were found to show higher expression of Cdk inhibitor p21 Waf/Cip1 (Ismail et al., 2006). Studies have also shown that genistein can trigger $\mathrm{G}_{2} / \mathrm{M}$ cell cycle arrest in human breast cancer (MDA-MB-231) cells via Ras/MAPK/activator protein-1 and consequently downregulating Cdk1, cyclin B1, and Cdc25C (Li et al., 2008). Further, it has been shown that genistein activated Chk1 and Chk2, which consequently inactivated Cdc25C and $\mathrm{Cdc} 25 \mathrm{~A}, \mathrm{Cdc} 2$, resulting in $\mathrm{G}_{2} / \mathrm{M}$ phase cell cycle arrest (Ouyang et al., 2009). In addition, genistein can induce $\mathrm{G}_{2} / \mathrm{M}$ cell cycle arrest and apoptosis via ATM/p53-dependent pathway in human colon cancer (HCT-116 and SW-480) cells. Genistein was found to cause the cell cycle arrest in the $G_{2} / M$ phase via ATM/p53 


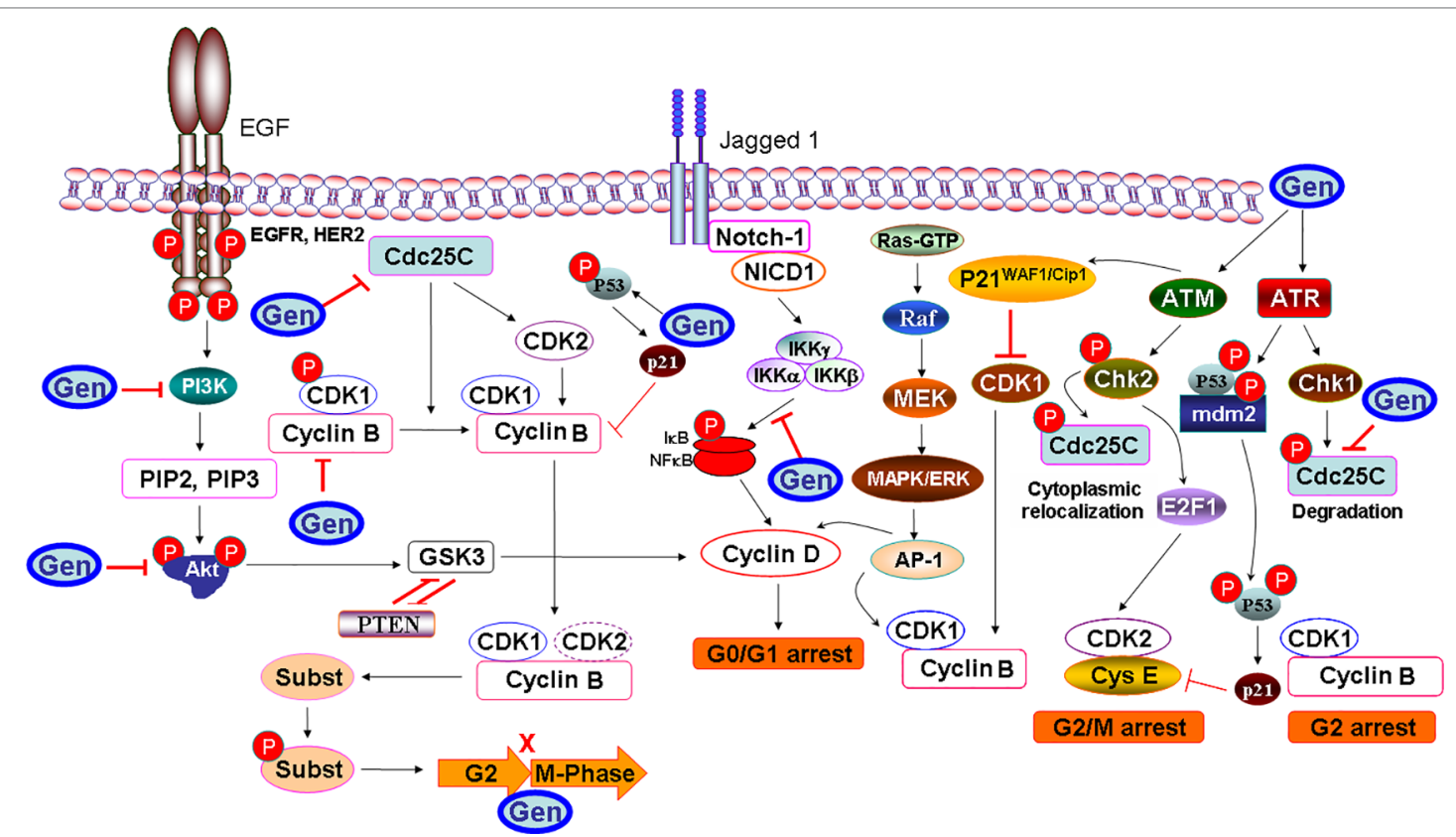

FIGURE 5 | Molecular targets of genistein (Gen) in cancer cell cycle. Although genistein activates the expression of ATM protein family and ATM-related (ATR), and further activates the checkpoint kinases Chk2 and Chk1, which in turn phosphorylate Cdc25C. However, genistein promotes cytoplasmic relocalization and or degradation of Cdc25C, which would prevent cyclin-dependent kinase 1 (Cdk1)/cyclin B from being dephosphorylated and cause G2 arrest. ATM may also modulate transcriptional regulation of cell cycle progression through modification the expression of p53 and Mdm2, or through activation of Chk2, which can further modulate p53, E2F1 expression, leading to an upregulation in the p21 expression that would inhibit Cdk2 activity. ATM also phosphorylates the p53 tumor suppressor though the induction of Cdk inhibitor p21 Waff/Cip1. Genistein also could inactivate phosphatidylinositol-3-kinase (PI3K)/serine/threonine kinase (Akt)/glycogen synthase kinase 3 (GSK3) signaling pathway, whether through the prevention of the phosphorylation of Act and upregulation of the prime time entertainment network (PTEN) expression. Genistein may also mediate cell cycle arrest by suppressing NF-kB-mediated activation of cyclin D1 expression.

and $\mathrm{p} 21^{\text {Waf1/Cip1 }}$. Additionally, the expression of Cdc2 and Cdc25A were also downregulated following genistein treatment (Zhang et al., 2013).

Such desired antiproliferative effect was also observed in normal human dermal fibroblasts, which would prevent scar formation in damaged and burned skin (Chin et al., 2000). This stringent ability of genistein to mediate cell cycle arrest in cancer cells would pose a question that does such cell cycle arrest is restricted to cancer and tumor tissue or could it be expanded to other non-malignant cells; or by other words, is the effect of genistein differ in other abnormal cases. In order to provide an answer for this question, it is very important to consider that although almost all cancer cells have mutations, other nonmalignant cells in the human body may carry mutations too. For instance mucopolysaccharidosis (MPS) type II fibroblasts are involved in inherited metabolic diseases caused by mutations that afflict the function of one of the degradation enzymes of glycosaminoglycans. The accumulation of such compounds in cells altered their proliferation and survival, ultimately leading to massive cellular dysfunctions. In fibroblasts derived from patients suffering from MPS types I, II, IIIA, and IIIB, genistein partially corrected the disturbances in the MPS II cell cycle and increased the tendency of MPS IIIA and IIIB fibroblasts to enter the $S$ and $G_{2} / M$ phases (Moskot et al., 2016). Collectively, these data revealed that genistein not only confer a protection against the proliferation of cancer cells, but it could also interact with other pathological cases in a different manner.

\section{Antiangiogenesis Effects}

Angiogenesis is characterized by the creation of new vessels from an existing vasculature, which being considered an important target in cancer treatment strategy. Since angiogenesis support the growth of cancer cells with vital factors, such as oxygen and nutrients, the inhibition of vasculature can be a pivotal strategy for cancer therapy. Previous studies have shown that genistein exhibited potent antiangiogenic properties. For example genisteintreated E6 and five human bladder cancer cell lines have exhibited anti-angiogenic effect via downregulating vascular endothelial growth factor (VEGF), platelet-derived growth factor, urokinase plasminogen activator, matrix metalloprotease-2 (MMP-2) and MMP-9 expression. Furthermore, natural vasculature inhibitors, such as plasminogen activator inhibitor-1, endostatin, angiostatin, and thrombospondin-1 were found to be activated (Su et al., 2005). In another study, it has been proposed that genistein-mediated suppression of VEGF via downregulation of c-Jun N-terminal kinase and p38, PTK/MAPK, and MMPs production (Yu et al., 2012). In another study, oral squamous cell carcinoma cells also demonstrated the downregulation of VEGF, basic fibroblast growth factor, and MMP-2 due to genistein treatment (Myoung et al., 2003). In addition, in vitro invasion assay and gelatin zymography using HSC-3 cells have also shown a decreased expression of VEGF. More recently, using thyroid cancer cells, a group of investigators revealed the downregulation of VEGF-A expression along with human telomerase reverse transcriptase, PTEN, 
NF- $\kappa B$, and p21 (Ozturk et al., 2018). All these antiangiogenic molecular mechanistic insights have been summarized in Figure 6. These results as mentioned above indicate that targeting VEGF may represent an effective key factor to deter the subsequent and deleterious effect of activation of its downstream molecular pathways. By blocking it, whether by specific inhibitors or by genistein, we can downregulate a panel of molecular pathways that aid cancer cells to establish de novo formation of blood vessels.

\section{Antimetastasis Effect}

The cancer metastasis is one of the most prominent causes of death worldwide. The metastasis of cancer is found to be dependent on higher expression of MMPs (Figure 7). In a study using nude mice, genistein was found to inhibit the metastasis of salivary adenoid cystic carcinoma cells (ACC) by inhibiting the VEGF and MMP-9 expression (Liu and Yu, 2004). Further evidences suggested that genistein displayed an inhibitory effect on the migration of MAT-LyLu and AT-2 rat prostate cancer cells (Miekus and Madeja, 2007).

The expression and phosphorylation of focal adhesion kinase (FAK) in hepatocellular carcinoma cells (MHCC-97H) were found to be decreased. Furthermore, in vivo xenograft transplantation of MHCC-97H cells have shown that number of pulmonary micrometastatic foci was significantly lowered in comparison to control group ( $\mathrm{Gu}$ et al., 2009). Studies using colon cancer cells (HCT116) revealed that genistein-mediated antimetastatic effects via inhibition of COX-2 and MMP-9, Ang-1, vasodilator-stimulated phosphoprotein (VASP) and VEGF (Kang et al., 2018). Other investigators have reported the

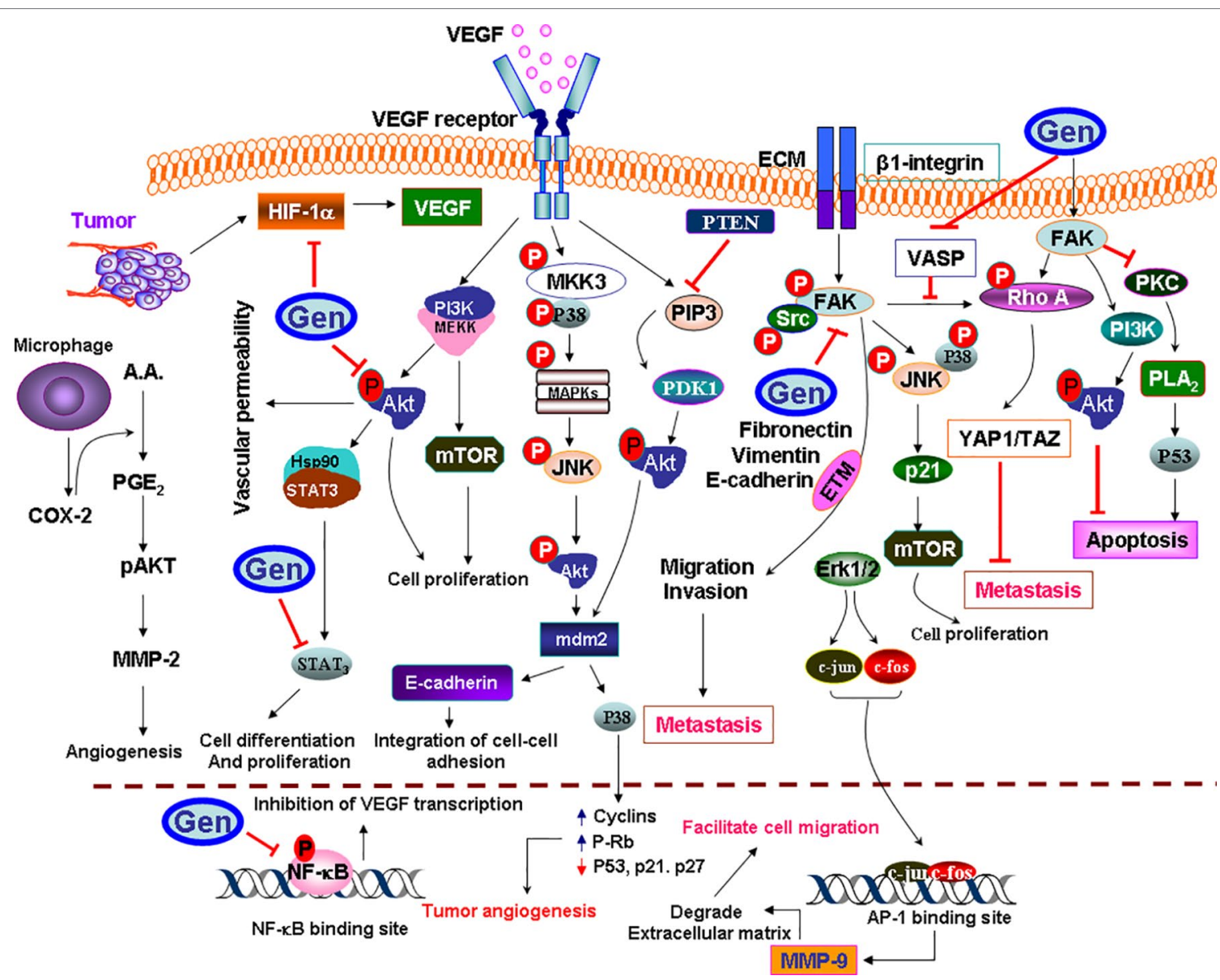

FIGURE 6 | Schematic representation of antiangiogenic activity of genistein (Gen) in cancer. Genistein inactivates each of mitogen-activated protein kinases (MAPK), activator protein-1 (AP-1), Akt/NF-кB, and Erk1/2 pathways, which abolished the downstream matrix metalloproteinase-9 (MMP-9) synthesis at the transcription level that declines the proteolytic activity and impairs the cellular migration. Although focal adhesion kinase (FAK) would prevent apoptosis through inactivation of the cytosolic phospholipase A2 (PLA2) and p53, but it would mediate apoptosis through the activation of PI3K/Act pathway. Genistein inhibits the activation of proangiogenic proteins (ERK/Akt/mTOR). Genistein could prevent cell differentiation and proliferation by increasing the activity of the tumor suppressor PTEN, which blocks Akt activation though PI3K dephosphorylation, and also dephosphorylate PIP3 into phosphatidylinositol 4,5-bisphosphate (PIP2). Genistein also prevents metastasis and enforces cancer cells to colonization in their site by phosphoprotein (VASP) upregulation. Since, VASP activates the extracellular matrix (ECM)mediated $\beta 1$-integrin-FAK-RhoA-YAP1-TAZ signaling to enhance YAP1/TAZ protein abundance. Genistein inactivates the epithelial-mesenchymal-transition (EMT) proteins, which promotes metastasis, including the proangiogenesis factors HIF-1 $\alpha$ and vascular endothelial growth factor (VEGF), all are upregulated by hypoxia. Genistein downregulates PI3K/Akt/HIF-1 $\alpha$ and NF-kB signaling pathways. Cycloxygenase-2 (COX-2) regulates the production of prostaglandin $E_{2}\left(P G E_{2}\right)$ from

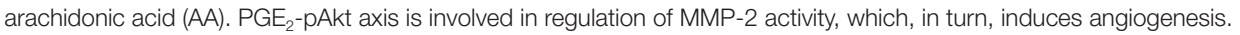


downregulation of ERK1/2, PI3K/Akt and MMP-2 in genisteintreated lung cancer cells (A549) (Noori-Daloii, 2012). Similarly, the downregulation of phosphorylated focal adhesion kinase, p-paxillin, tensin-2, vinculin, and $\alpha$-actinin has been observed in genistein-treated melanoma cells (B16F10). Furthermore, the expression of Snail, an epithelial-to-mesenchymal transition transcription factor was found to be decreased following genistein treatment (Cui et al., 2017).

Unlike specific chemotherapeutic drugs, which target specific pathway, the mechanism of genistein is wide and involve a spectrum of molecular pathways. All these effects of genistein could increase its antimetastatic effect and deter the invasion and spread of tumor cells into other tissues which, at least, may alleviate the pain and suffering of cancer patients.

\section{Anti-Inflammatory and Antioxidant Effects}

It is well understood that inflammatory behavior is closely related to cancer development. Cancer cells express a variety of inflammatory mediators, such as cytokines and chemokines. Literature suggested that anticancer drugs can be used to treat inflammatory responses. Previous studies have reported the inhibitory effect of genistein on signal transducer and activator of transcription 1 and NF- $\kappa \mathrm{B}$-mediated signaling cascade in activated macrophages (Hamalainen et al., 2007). Other researchers reported that genistein suppressed inflammatory responses through inhibition of COX-2, phosphorylated c-Jun N-terminal kinase (JNK), protein kinase R-like ER kinase, and pp38 and in vitro and in vivo studies MCF-7 breast cancer cell line and mammary glands of female rats, respectively, (Hwang et al., 2009). Studies

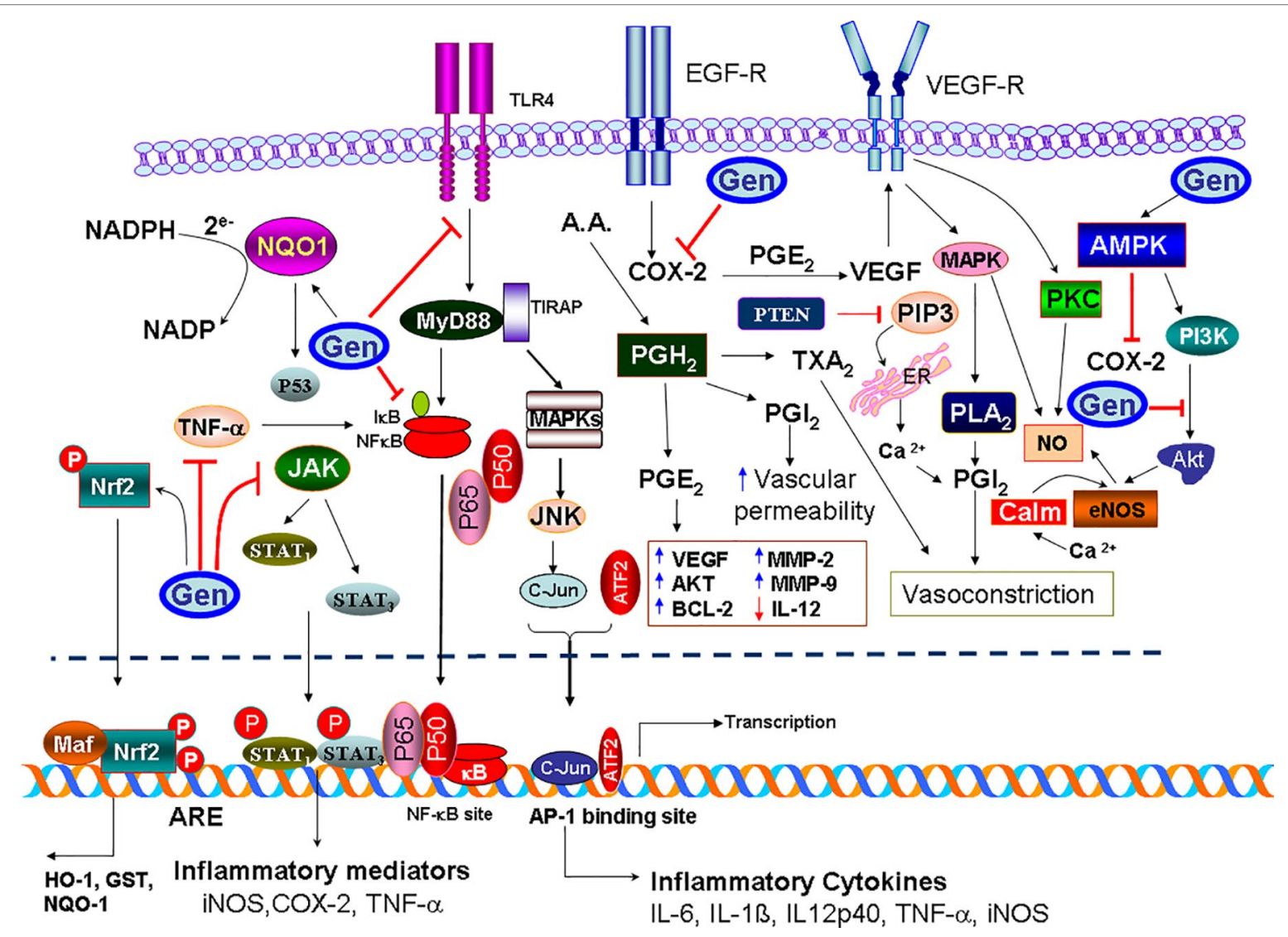

FIGURE 7 | Illustration of antimetastatic potential of genistein (Gen) in cancer. Genistein activates genistein-mediated activated protein kinase (AMPK)/mitogen-activated protein kinase (MAPK)/protein kinase C (PKC) pathways; the downstream of these sequences is the activation of neuronal nitric oxide synthase (nNOS), which activates the production of NO that possess a strong antioxidant/anti-inflammatory activity. Genistein also inhibits the activity of cycloxygenase-2 (COX-2), whether through the activation of AMPK pathway, or by inactivation of PIP3 pathway. Notably, COX-2 causes upregulation of vascular endothelial growth factor (VEGF) and VEGF-R activation. Further, the overexpression of $\mathrm{COX}-2$ promotes the production of $\mathrm{PGH}_{2}$, which further metabolized to prostaglandin $E_{2}\left(P G E_{2}\right)$, prostacyclin (PGI2), and thromboxane $\mathrm{A}_{2}\left(\mathrm{TXA}_{2}\right)$. Genistein inactivates TLR4 dimerization, thus abolishes MyD88 or TIR-domain-containing adapter-inducing interferon- $\beta$ (TRIF) to activate nuclear factor-kB (NF-kB), so inhibit its translocation into the nucleus, and that prevents the upregulation of proinflammatory cytokines. Genistein possesses a strong inhibitory effect on oxidative stress by activating the nuclear factor erythroid 2-related factor 2 (Nrf2)-heme oxygenase-1 (HO-1)/NAD(P)H dehydrogenase (quinone) 1 (NQO1) pathway. Since, genistein is able to activate the Nrf2/NQO1 pathway. After being phosphorylated, Nrf2 activates antioxidant response element (ARE) and enhances transcription of Nrf2-regulated genes including NQO-1, HO-1, and glutathione S-transferase (GST). Also, Genistein has a potent anti-inflammatory effect through prevention of tumor necrosis factor- $\alpha$ (TNF- $\alpha$ )-induced NF-kB translocation into the nucleus, and inhibition of MAPKs/c-Jun N-terminal kinase (JNK)/c-Jun pathway, which decline the induction of the inflammatory mediators. Genistein also abolishes the activation of signal transducer and activator of transcription 1 (STAT1)/ signal transducer and activator of transcription 3 (STAT3) and prevents their translocation into the nucleus through downregulating the activity of JNK. 
using RAW 264.7 macrophages and MH7A human synoviocyte cells have also reported the downregulation of inflammatory mediators, such as IL- $1 \beta$, IL-6, IL-8, TNF- $\alpha$, IL-6, and NF- $\kappa$ B (Ji et al., 2012; Li et al., 2014). In addition, genistein was found to attenuate proinflammatory responses in lipopolysaccharideinduced microglia cells (BV2). Genistein repressed the production of $\mathrm{NO}$ and prostaglandin $\mathrm{E}_{2}$ by downregulating the expression of nitric oxide synthase and COX-2 in microglial cells. In addition, the expression of inflammatory cytokines, including IL- $1 \beta$ and TNF- $\alpha$, were also markedly suppressed by genistein through inactivation of NF- $\kappa$ B and toll like receptor-4 (Jeong et al., 2014). The administration of genistein (1.04 or $1.3 \mathrm{mg} /$ day) was found to lower the expression of TNF- $\alpha$ and IL- 6 in a murine model of peritoneal endometriosis, indicating its ability to inhibit the development of inflammation (Sutrisno et al., 2018). More recently, researchers have reported the anti-inflammatory and anticancer response of long-term genistein treatment in diethylnitrosamineinduced hepatocellular carcinoma in mice (Lee et al., 2019). In conclusion, it's very clear that the possible clinical application of genistein as an anti-inflammatory agent could be due to its ability to block many inflammatory cascades that help cancer cells to create their own and independent microenvironment. The inhibition or attenuation of the inflammatory mediators, which encompass growth factors, chemokines, and cytokines, could suppress the function of cancer cells.

In other context, free radicals are constantly produced during oxidative stress, and they are known to be highly toxic and have a deleterious effect on the cellular and enzymatic integrity. Genistein plays an important role on recycling enzymes, which are known as body's main antioxidant constituents. For instance, genistein induced activation of antioxidant enzymes through AMPK and PTEN pathways in prostate cancer cells (DU145). Genistein also stimulated the expression of the manganese superoxide dismutase and catalase, which collectively led to significant reduction in reactive oxygen species levels (Park et al., 2010). In vivo, genistein exposure governed the non-enzymatic antioxidant action by increasing the expression of glutathione and $\mathrm{NAD}(\mathrm{P}) \mathrm{H}$ dehydrogenase (Wiegand et al., 2009; Vanhees et al., 2013). In another study, researchers revealed that genistein possessed inhibitory action on cancer-associated enzyme, ornithine decarboxylase, and considerably suppressed skin carcinogenesis stimulated by ultraviolet light in a mice model (Record et al., 1995; Mazumder and Hongsprabhas, 2016).

As described above, there is a complex interference between the inflammatory mediators and oxidative stress. Collectively or separately, each potentiate the production of the other, and both worsen the status of cancer patients. As discussed above, genistein has the potency to attenuate the inflammatory mediators aside its ability to increase the activity of many antioxidant enzymes. That could be helpful in battle against cancer to improve the lifestyle of cancer patients and relieve their pain due to such inflammation. Nevertheless, further clinical studies are required to investigate the therapeutic potential of genistein in cancer patients.

\section{Genistein and miRNA}

The microRNAs (miRNAs) are a class of small noncoding RNAs, consisting of 19-24 nucleotides, which regulate almost $60 \%$ of genes in the human genome (Macfarlane and Murphy, 2010). Emerging pieces of evidence have suggested that miRNAs are deregulated in almost all human cancers, and found to involve in a wide spectrum of cancer hallmarks, such as sustained proliferative signaling, evasion of growth suppressors, activated invasion and metastasis, replicative immortality, angiogenesis, resistance to cell death, and evasion of immune destruction (Van Roosbroeck and Calin, 2017). Based on previous studies, miRNAs have also been widely proposed as potential targets for treating various cancers. So, it is very important to know how genistein influences the expression and regulation of miRNAs in human cancer cells.

Recently, Lynch and colleague (2016) have demonstrated that following treatment with $40 \mu \mathrm{M}$ genistein for 7 days in PC3 prostate cancer cell line, the expression of miR-200c significantly increased, while the methylation levels of miR-200c gene get reduced (Lynch et al., 2016). Genistein can affect and regulate the expression of noncoding RNAs, especially microRNAs (miRNAs), in cancer cells (Table 2).

The miR-200 family was found to act as a tumor-suppressive group of miRNAs that targets ZEB1, ZEB2, and Slug genes, which drive epithelial-mesenchymal-transition and tumor progression in prostate cancer cells (Mongroo and Rustgi, 2010; Liu et al., 2013; Feng et al., 2014). Similarly, in another study, it was demonstrated that after treatment with $25 \mu \mathrm{M}$ genistein for 4 days in PC3 and DU145 prostate cancer cell lines, the level of miR-1260b expression was significantly decreased ( 2 -fold) compared to nongenistein treated cells (Hirata et al., 2014). The miRNA-1260b expression in human prostate cancer cell lines was found to be significantly higher in prostate cancer tissue and cells with concomitant increase in cell proliferation, migration, and invasive capacity of prostate cancer cells (Hirata et al., 2014).

Mechanistically, genistein exerted its antitumor effect via downregulation of miR-1260b that targets sRRP1 and Smad4 genes via DNA methylation or histone modifications, at least in part in prostate cancer cells (Hirata et al., 2014). Similarly, in another study, it was shown that treatment of PC3 and DU145 cells with $25 \mu \mathrm{M}$ genistein downregulated the expression of miR-151. Inhibition of miR-151 in prostate cancer cells by genistein significantly suppressed cell migration and invasion (Chiyomaru et al., 2012). It was also found that genistein upregulated the tumor suppressor miR-574-3p expression and significantly affected cell proliferation, migration, and invasion in prostate cancer cell lines (Chiyomaru et al., 2013) In the case of breast cancer, $5 \mu \mathrm{M}$ of genistein significantly reduced $(\sim 1.8$-fold) the oncogenic miR-155 expression in MDA-MB-435 cells (De la Parra et al., 2016). In parallel with the reduction of miR155 , the levels of proapoptotic and antiproliferative proteins, such as forkhead box 03, PTEN, casein kinase, and p27, also get upregulated in MDA-MB-435 cells in response to genistein treatment. In the case of laryngeal cancer, it has shown that genistein induced the expression of miR-1469, which, in turn, promoted cell apoptosis and inhibited the expression of myeloid cell leukemia 1, an antiapoptotic member of the Bcl-2 family of apoptosis-regulating proteins, thus preventing human laryngeal cancer (Ma et al., 2018). In the case of multiple myeloma cells, it was observed that following treatment with genistein $(40 \mu \mathrm{M})$ for $48 \mathrm{~h}$, the expression of miR-29b in U266 multiple myeloma cells was significantly increased (two-fold) (Xie et al., 2016). It was further demonstrated that miR-29b significantly 
TABLE 2 | Effect of genistein on cancer-associated microRNAs (miRNAs).

\begin{tabular}{|c|c|c|c|c|c|}
\hline Cancer & Cell lines & $\begin{array}{l}\text { Duration of treatment } \\
\text { with concentration }\end{array}$ & $\begin{array}{l}\text { Effect on miRNA } \\
\text { expression with fold } \\
\text { change }\end{array}$ & $\begin{array}{l}\text { Gene/Proteins/ } \\
\text { Pathways affected }\end{array}$ & References \\
\hline \multirow[t]{6}{*}{ Prostate cancer } & PC3 & 7 days $(40 \mu \mathrm{M})$ & $\uparrow m i R-200 c$ & ZEB1 & Lynch et al. (2016) \\
\hline & & & & ZEB2 & $\begin{array}{l}\text { Mongroo and Rustgi } \\
\text { (2010) }\end{array}$ \\
\hline & & & & Slug & Liu et al. (2013) \\
\hline & & & & EMT & Feng et al. (2014) \\
\hline & PC3, & 4 days $(25 \mu \mathrm{M})$ & $\downarrow \mathrm{miR}-1260 \mathrm{~b}$ & sRRP1 & Chiyomaru et al. (2012); \\
\hline & DU145 & & $\begin{array}{l}\text { ( 2-fold); } \downarrow \text { miR-151; } \uparrow m i R- \\
574-3 p\end{array}$ & Smad4 & $\begin{array}{l}\text { Chiyomaru et al. (2013); } \\
\text { (Hirata et al., 2014) }\end{array}$ \\
\hline Breast cancer & MDA-MB-435 & $48 \mathrm{~h}(5 \mu \mathrm{M})$ & $\begin{array}{l}\downarrow \mathrm{miR}-155 \\
(\sim 1.8-\text { fold })\end{array}$ & $\begin{array}{l}\text { Forkhead box 03, PTEN, } \\
\text { casein kinase and p27 }\end{array}$ & De la Parra et al. (2016) \\
\hline Human Laryngeal cancer & & & $\uparrow m i R-1469$ & Mcl1 & Ma et al. (2018) \\
\hline Multiple myeloma & U266 & 2 days $(40 \mu \mathrm{M})$ & $\begin{array}{l}\uparrow m i R-29 b \\
\text { ( 2-fold })\end{array}$ & $N F-\kappa B$ & Xie et al. (2016) \\
\hline Pancreatic cancer & & & $\downarrow \mathrm{miR}-223$ & $\begin{array}{l}\text { F-box/WD repeat- } \\
\text { containing protein } 7 \text { gene }\end{array}$ & (Ma et al., 2013) \\
\hline
\end{tabular}

inhibited NF- $\mathrm{BB}$ expression and increased apoptosis in U266 multiple myeloma cells (Xie et al., 2016). In pancreatic cancer cells, genistein treatment significantly inhibited miR-223 expression and upregulated F-box/WD repeat-containing protein 7 gene, one of the targets of miR-223 (Ma et al., 2013). Through the above studies, one can conclude that genistein induces or reduces the expression of miRNAs in cancer cells. Nevertheless, further investigations are still required to unravel the precise mechanism of action of genistein on miRNAs regulation.

\section{Combinatorial and Clinical Studies Using Genistein}

Genistein exhibited synergistic apoptotic and anti-inflammatory effects with capsaicin in MCF-7 human breast cancer cells by modulating AMPK and COX-2 (Hwang et al., 2009). In HepG2 human hepatocellular carcinoma cells, the extent of apoptosis was maximal when genistein exposure for $24 \mathrm{~h}$ was followed by oestradiol treatment for $48 \mathrm{~h}$ as compared to either of the agents alone (Sanaei et al., 2017). Moreover, genistein potentiated the anticancer action of chemotherapeutic drug 5-fluorouracil in MIA PaCa-2 human pancreatic cancer cells by increasing both apoptotic as well as autophagic cell death. Studies in animals transplanted with MIA PaCa-2 cells also confirmed these observations, revealing a significant decrease in tumour volume with combined treatment regimen (Suzuki et al., 2014). In addition, efficacy of photofrin-mediated photodynamic therapy to induce apoptosis was considerably enhanced by genistein against SK-OV-3 human ovarian cancer and SNU 80 human anaplastic thyroid cancer cells (Ahn et al., 2014). These effects were regulated by activation of the general apoptotic signaling cascade requiring activation of caspase- 8 and caspase-3 (Ahn et al., 2012; Ahn et al., 2014).

In view of chemopreventive potential of genistein based on in vitro and in vivo studies, genistein research has been upscaled to study its safety and efficacy in clinical trials either individually or in combination with other chemotherapeutic agents. Although there are only few clinical trials that have attempted to study the safety and efficacy of genistein, these studies have presented promising results which are being summarized in this section. In a 12-month, randomized, placebo-controlled study, Atteritano et al. (2008) investigated the effect of genistein at a dose of 54 $\mathrm{mg} /$ day on cytogenetic biomarkers in peripheral lymphocytes of postmenopausal women $(n=57)$ and reported that the administration of genistein effectively reduced cytogenetic markers. Following 1-year of genistein administration, sister chromatid exchange rate was $3.98 \pm 1.14(\mathrm{p}<0.05)$, high frequency cells count dipped to $3 \%$ from initial count of $5 \%$ and chromosomal aberration frequency was documented to be $4.5 \%$ ( $\mathrm{p}<0.05)$, emphasizing the positive effect on reduction of cytogenetic biomarkers. In another randomized, double-blind, placebo controlled study, the administration of genistein in postmenopausal women with type 2 diabetes mellitus $(n=28)$ was reported to improve fasting blood glucose, serum triglyceride, glycated hemoglobin, and malondialdehyde levels along with control of oxidative stress levels (Braxas et al., 2019). Similar results were reported from another study where use of genistein in a randomized, double blind, placebo-controlled clinical trial was reported to be safe for postmenopausal women (Delmanto et al., 2013). In another phase I/II pilot study $(n=13)$, genistein in combination with FOLFOX/ FOLFOX-bevacizumab was found to be safe and torable for metastatic colorectal cancer patients with $61.5 \%$ overall response rate and 11.5 months of median progression free survival (Pintova et al., 2019). Schneider et al. (2019) reported safety profile of administration of PhytoSerum (containing genistein, daidzein, and S-equol) in a phase $1 / 2$ a randomized clinical trial, where the formulation at daily dose of 50 or $100 \mathrm{mg}$ was well tolerated by perimenopausal women. In a phase I dose escalation study in pancreatic cancer patients $(n=16)$, administration of AXP107-11 (crystalline form of genistein) along with gemcitabine illustrated favorable pharmacokinetic profile with mean overall survival of 4.9 months (Lohr et al., 2016). In presurgical bladder cancer patients (phase 2 trial of genistein), genistein was shown to be more effective at a lower dose to reduce EGFR phosphorylation in bladder cancer tissue (Messing et al., 2012). The safety and efficacy of genistein was further documented from another double-blind phase 2 clinical trial in localized prostate cancer patients (Lazarevic 
et al., 2011). These studies depict the chemopreventive nature of genistein and its safety and efficacy alone or in combination with other chemotherapeutic agents. These initial results from clinical studies further strengthen the potential of genistein as a chemopreventive drug and encourages further studies.

\section{CURRENT LIMITATION AND CHALLENGES}

Despite knowledge gained and discussed above and the tremendous clinical success in cancer therapy in the present era, the clinical application of genistein as a promising therapeutic agent for cancer treatment is not fully understood. However, one of the major limitations of currently available anticancer drugs is the ability of cancer cells to develop chemoresistance against such drugs. Cancer cells are able to produce multidrug resistance proteins, such as multidrug resistance protein 1 , and multidrug resistance-associated protein 1 (ABCC1), which causes drug resistance. Therefore, chemoresistance represents a serious clinical obstacle in effectively treating cancer patients. Polo-like kinase 1 (Plk1) has been shown to be involved in chemoresistance, so Plk1-targeted therapies could possibly reduce or eliminate the chemoresistance of cancer cells against anticancer drugs. Genistein was proposed as a Plk1 inhibitor, which effectively downregulates the expression of multidrug resistance protein 1 and multidrug resistance-associated protein 1 , key factors inducing chemoresistance in paclitaxel-resistant cancer cells (Shin et al., 2019). The discovery of genistein being a Plk1 inhibitor adds a new horizon for the possible application of genistein as adjuvant in chemotherapy because of its ability to prevent cancer cells from acquiring resistance against the anticancer drugs or due to resensitize drug-resistant cancer cells.

The other limitation in our knowledge is that as a natural compound genistein may represent a raw material we can further work on, to improve its characters, which may improve the quality of lifestyle of cancer patients. For instance, in a murine xenograft study using human prostate cancer cell lines, the synthetic genistein nanosuspension (BIO 300) improves the therapeutic index in prostate cancer treatment by preventing radiation-induced erectile dysfunction without reducing tumor radiosensitivity (Jackson et al., 2019). In fact the low aqueous solubility of genistein is the major problem that limits the clinical development and applications of genistein, thus modification of its chemical structure can improve its aqueous solubility and contribute to higher bioavailability (Tang et al., 2019). Additionally, the stability of genistein is another critical factor which affects its bioavailability. Methylation of the free hydroxymethyl group of genistein enhances its metabolic stability and improves the membrane transportation capacity (Chiang et al., 2017). The question is that as one of the main dietary source of genistein, can we increase the health benefits of soybean. Based on the available knowledge, yet that question has not been answered. However, a recent study may partially give us an avenue for this purpose. Treatment of soybeans with ultrasound increased its isoflavone contents and improved the functional properties related to their health benefits (e.g. increased bioactivity as radical scavengers and by reducing the activation of NF- $\kappa$ B (Falcao et al., 2019). As discussed above, the clinical importance of NF- $\kappa \mathrm{B}$ activation is derived mainly from its role in inflammatory responses and apoptosis cascades. Fermentation also has been suggested as a possible way to improve the bioavailability of genistein and further accelerates its absorption (Lee et al., 2017). But again one can ask the question whether such increase in the bioavailability of isoflavones in soybeans is safe. That is in fact dependent on the level of dietary intake of isoflavones. In a randomized double-blind parallel study in men with type- 2 diabetes mellitus, and in a double-blind randomized parallel study on bone turnover markers in women within 2 years of onset of menopause, the high-dose isoflavone intake impaired thyroid function (Sathyapalan et al., 2017a; Sathyapalan et al., 2017b). There are also inherent challenges in the effectiveness of genistein on different human cohorts. In a study monitoring the short-term versus long-term effect of genistein treatment in prostate cancer, short term treatment of PC3-M cells (metastatic prostate cancer cells) in vitro over a period of 8 weeks decreased MMP-2 expression whereas long-term treatment up to 2 months increased MMP-2 levels, emphasizing the fact that early phase chemoprevention trails need to be closely monitored for optimal dose administration duration for maximum efficacy (Zhang et al., 2019). These data indicate that biomarker expression can change as a function of treatment time. Therefore, there is still an urgent need for performing further studies to optimize the effective doses and the best route of administration for genistein, whether in cancer therapy and other types of illnesses. Further, genistein is known as a strong antioxidant compound and can provide protection against oxidative stress in various noncancerous tissues. For instance, treatment with genistein was shown to preserve follicular quality in rats with polycystic ovary syndrome by elevating antioxidant capacity (Rajael et al., 2019), increased the total antioxidant activities and reduced kidney damages in nephrotic rats (Javanbakht et al., 2014), or improved antioxidant status and decreased pancreatic damage following administration of nicotine to mice (Salahshoor et al., 2019). In concert with its multitargeted anticancer activities, protective action of genistein on adjacent normal healthy tissues makes this natural isoflavone an attractive key compound for development of novel and more effective drug for combating malignant disorders in the future.

\section{CONCLUSIONS AND FUTURE PERSPECTIVES}

The present manuscript extensively reviewed the available scientific literature on the potential role of genistein as an anticancer agent with detailed description of its targets in signaling cascades. The in vivo and in vitro studies further emphasized the chemopreventive potential of genistein, in view of which genistein has been upscaled to clinical trials. This is mainly promising for the patients in developing countries where currently marketed therapies for cancer treatment are very expensive and beyond the reach of patients, thereby limiting the affordability of treatment options. Thus, developing countries are desperately looking for 
low cost options for cancer treatment and prevention, of which natural products as anticancer agents seem promising. This further emphasizes the need to develop safe and effective natural product-derived agents as chemopreventive drugs which are easily available. Genistein (an isoflavone) is one among bioactive natural molecules with aromatic substitution at carbon C3 instead of the $\mathrm{C} 2$ position as it is common for other types of flavonoids. Considering the involvement of genistein in a wide-variety of molecular pathways, there is a greater need to understand this key molecule in terms of its regulatory role as well as its therapeutic potential. The clinical and experimental evidences gathered in this review are suggestive of the promising therapeutic role of genistein in the treatment and prevention of different types of cancer and encourage further in vivo studies with this attractive natural molecule. More recently, (Shaji, 2018) investigated the interactions of genistein with monocarboxylate transporter-8 to treat AllanHerndon-Dudley syndrome. A very recent study has shown the promising role of genistein in combination with chemotherapeutic drug FOLFOX to treat metastatic colorectal cancer (Pintova et al., 2019). Therefore synergistic approaches using genistein may help in near future to treat grave diseases, such as cancer.

Although we have a come a long way ahead in cancer treatment modalities, we still have unexplored dimensions to scale for modulating effective treatment strategies for cancer patients with long-term safety and efficacy. Natural products, such as genistein, have been extensively studied for its anticancer effects which are summarized in this review. However, we still have a long way to go. First, besides the known molecular targets as therapeutic modulators, further clinical studies on large patient cohorts are required to extensively study the chemopreventive and therapeutic potential of genistein in conjunction with its long-term safety and efficacy in treating cancer patients. The drug-drug interactions of genistein with other chemotherapeutic agents need to extensively studies on both experimental and clinical front to maximize the efficacy and minimize drug resistance and risk of replase. Secondly, the possible mechanism and strategies for increasing the accessibility and bioavailability of genistein need to be explored

\section{REFERENCES}

Ahn, J.-C., Biswas, R., and Kim, J.-S. (2014). The enhanced apoptotic effect of photodynamic therapy using photofrin combined with genistein in human ovarian cancer cell SK-OV-3. Biomed. Res. 25, 51-57. (0970-938X).

Ahn, J. C., Biswas, R., and Chung, P. S. (2012). Combination with genistein enhances the efficacy of photodynamic therapy against human anaplastic thyroid cancer cells. Lasers Surg. Med. 44, 840-849. doi: 10.1002/1sm.22095

Ardito, F., Di, G. G., Pellegrino, M. R., and Muzio, L. L. (2018). Genistein as a potential anticancer agent against head and neck squamous cell carcinoma. Curr. Top. Med. Chem. 18, 174-181. doi: 10.2174/1568026618666180116122650

Atteritano, M., Pernice, F., Mazzaferro, S., Mantuano, S., Frisina, A., D’anna, R., et al. (2008). Effects of phytoestrogen genistein on cytogenetic biomarkers in postmenopausal women: 1 year randomized, placebo-controlled study. Eur. J. Pharmacol. 589, 22-26. doi: 10.1016/j.ejphar.2008.04.049

Baker, W., and Robinson, R. (1928). CCCCVIII.-Synthetical experiments in the iso flavone group. Part III. A synthesis of genistein. J. Chem. Soc. (Resumed), 3115-3118. doi: 10.1039/JR9280003115 in more details. Thirdly, the precise therapeutic dose of genistein for treatment of different cancer types needs to be standardized. Fourthly, the duration and time of genistein dose administration need extensive standardization based on variable effects reported in long-term and short-term treatment administration regimens. Furthermore, the role of nanotechnology should also be explored in future to reduce the required dosses of genistein and to specifically target tumor tissues using novel drug delivery techniques. Recently, using encapsulated genistein nanomaterials, Pool et al. (2018) have investigated the promising anticancer potential of genistein in HT29 human colon cancer cells via activation of apoptosis and autophagy along with $\mathrm{H}_{2} \mathrm{O}_{2}$ production. In addition, the utilization of molecular docking studies to uncover the hidden mechanisms of action of genistein should also be explored. Hence, extensive preclinical research along with clinical studies needs to be designed and executed before genistein is incorporated as one of the mainstream treatment of choices for cancer. In view of available literature, genistein presents as a promising chemopreventive drug specially with respect to management of drug resistance in cancer patients which is of clinical interest. Nevertheless, extensive work needs to be done to translate the therapeutic efficacy of genistein from bench to bedside.

\section{AUTHOR CONTRIBUTIONS}

HT performed literature survey and data extraction. MT contributed sections on apoptosis, cell cycle arrest, antiangiogenesis, anti-inflammatory and conclusion and also created figures of the indicated sections. FT participated in data extraction. KS extracted data and wrote the abstract and introduction section. MK prepared the section on the chemistry of genistein. AS and VA proofread the manuscript. US and AJ composed the text on miRNA and genistein. VA and HT revised the manuscript. $\mathrm{AB}$ critically reviewed and edited the manuscript and also made suggestions for improvements. All authors read and approved the final manuscript.

Banerjee, S., Li, Y., Wang, Z., and Sarkar, F. H. (2008). Multi-targeted therapy of cancer by genistein. Cancer Lett. 269, 226-242.

Bi, Y. L., Min, M., Shen, W. and Liu, Y. (2018). Genistein induced anticancer effects on pancreatic cancer cell lines involves mitochondrial apoptosis, G0/G1 cell cycle arrest and regulation of STAT3 signalling pathway. Phytomedicine 39, 10-16.

Bishayee, A. (2012). Editorial: current advances in cancer prevention and treatment by natural products. Curr. Pharm. Biotechnol. 13, 115-116. doi: 10.2174/ 138920112798868629

Braxas, H., Rafraf, M., Karimi Hasanabad, S., and Asghari Jafarabadi, M. (2019). Effectiveness of genistein supplementation on metabolic factors and antioxidant status in postmenopausal women with type 2 diabetes mellitus. Can. J. Diabetes. 490-497. doi: 10.1016/j.jcjd.2019.04.007

Chae, H.-S., Xu, R., Won, J.-Y., Chin, Y.-W., and Yim, H. (2019). Molecular Targets of genistein and its related flavonoids to exert anticancer effects. Int. J. Mol. Sci. 20, 2420. doi: 10.3390/ijms20102420

Chiang, C. M., Chang, Y. J., Wu, J. Y., and Chang, T. S. (2017). Production and anti-melanoma activity of methoxyisoflavones from the biotransformation of 
Genistein by two recombinant Escherichia coli strains. Molecules 22, 87. doi: $10.3390 /$ molecules 22010087

Chin, G. S., Liu, W., Steinbrech, D., Hsu, M., Levinson, H., and Longaker, M. T. (2000). Cellular signaling by tyrosine phosphorylation in keloid and normal human dermal fibroblasts. Plast. Reconstr. Surg. 106, 1532-1540. doi: 10.1097/00006534-200012000-00014

Chiyomaru, T., Yamamura, S., Fukuhara, S., Hidaka, H., Majid, S., Saini, S., et al. (2013). Genistein up-regulates tumor suppressor microRNA-574-3p in prostate cancer. PloS One 8, e58929. doi: 10.1371/journal.pone.0058929

Chiyomaru, T., Yamamura, S., Zaman, M. S., Majid, S., Deng, G., Shahryari, V., et al. (2012). Genistein suppresses prostate cancer growth through inhibition of oncogenic microRNA-151. PloS One 7, e43812. doi: 10.1371/journal. pone. 0043812

Crawford, S. (2013). Is it time for a new paradigm for systemic cancer treatment? Lessons from a century of cancer chemotherapy. Front. Pharmacol. 4, 68. doi: 10.3389/fphar.2013.00068

Cui, S., Wang, J., Wu, Q., Qian, J., Yang, C., and Bo, P. (2017). Genistein inhibits the growth and regulates the migration and invasion abilities of melanoma cells via the FAK/paxillin and MAPK pathways. Oncotarget 8, 21674-21691. doi: 10.18632/oncotarget.15535

Das, A., Banik, N. L., and Ray, S. K. (2010). Flavonoids activated caspases for apoptosis in human glioblastoma T98G and U87MG cells but not in human normal astrocytes. Cancer 116, 164-176. doi: 10.1002/cncr.24699

De La Parra, C., Castillo-Pichardo, L., Cruz-Collazo, A., Cubano, L., Redis, R., Calin, G. A., et al. (2016). Soy isoflavone Genistein-mediated downregulation of miR-155 contributes to the anticancer effects of Genistein. Nutr. Cancer 68, 154-164. doi: 10.1080/01635581.2016.1115104

Delmanto, A., Nahas-Neto, J., Traiman, P., Uemura, G., Pessoa, E. C., and Nahas, E. A. (2013). Effects of soy isoflavones on mammographic density and breast parenchyma in postmenopausal women: a randomized, double-blind, placebo-controlled clinical trial. Menopause 20, 1049-1054. doi: 10.1097/ GME.0b013e3182850270

Denis, J. D. S., Gordon Iv, J. S., Carroll, V. M., and Priefer, R. (2010). Novel synthesis of the isoflavone genistein. Synthesis 2010, 1590-1592. doi: 10.1055/s-0029-1219757

Dhandayuthapani, S., Marimuthu, P., Hormann, V., Kumi-Diaka, J., and Rathinavelu, A. (2013). Induction of apoptosis in HeLa cells via caspase activation by resveratrol and genistein. J. Med. Food 16, 139-146. doi: 10.1089/ jmf.2012.0141

Falcao, H. G., Silva, M. B. R., De Camargo, A. C., Shahidi, F., Franchin, M., Rosalen, P. L., et al. (2019). Optimizing the potential bioactivity of isoflavones from soybeans via ultrasound pretreatment: Antioxidant potential and NF-kappaB activation. J. Food Biochem. 43, e13018. doi: 10.1111/jfbc.13018

Feng, X., Wang, Z., Fillmore, R., and Xi, Y. (2014). MiR-200, a new star miRNA in human cancer. Cancer Lett. 344, 166-173. doi: 10.1016/j.canlet.2013.11.004

Frey, R. S., Li, J., and Singletary, K. W. 2001. Effects of genistein on cell proliferation and cell cycle arrest in nonneoplastic human mammary epithelial cells: involvement of Cdc2, p21waf/cip1, p27kip1, and Cdc25C expression. Biochem. Pharmacol. 61, 979-989.

Ganai, A. A., and Farooqi, H. (2015). Bioactivity of genistein: a review of in vitro and in vivo studies. BioMed. Pharmacother. 76, 30-38. doi: 10.1016/j. biopha.2015.10.026

Goj, K., Rusin, A., Szeja, W., Kitel, R., Komor, R., and Grynkiewicz, G. (2012). synthesis of genistein 2, 3-Anhydroglycoconjugates ń potential antiproliferative agents. Acta Pol. Pharm. 69, 1239-1247.

Gu, Y., Zhu, C. F., Dai, Y. L., Zhong, Q., and Sun, B. (2009). Inhibitory effects of genistein on metastasis of human hepatocellular carcinoma. World J. Gastroenterol. 15, 4952-4957. doi: 10.3748/wjg.15.4952

Hamalainen, M., Nieminen, R., Vuorela, P., Heinonen, M., and Moilanen, E. (2007). Anti-inflammatory effects of flavonoids: genistein, kaempferol, quercetin, and daidzein inhibit STAT-1 and NF-kappaB activations, whereas flavone, isorhamnetin, naringenin, and pelargonidin inhibit only NF-kappaB activation along with their inhibitory effect on iNOS expression and NO production in activated macrophages. Mediators Inflammation 2007, 45673. doi: $10.1155 / 2007 / 45673$

Hamza Sherif, S., and Gebreyohannes, B. (2018). Synthesis, characterization, and antioxidant activities of genistein, biochanin A, and their analogues. J. Chem. 2018, 4032105. doi: 10.1155/2018/4032105
Hirata, H., Hinoda, Y., Shahryari, V., Deng, G., Tanaka, Y., Tabatabai, Z. L., et al. (2014). Genistein downregulates onco-miR-1260b and upregulates sFRP1 and Smad4 via demethylation and histone modification in prostate cancer cells. $\mathrm{Br}$. J. Cancer 110, 1645-1654. doi: 10.1038/bjc.2014.48

Horia, E., and Watkins, B. A. (2007). Complementary actions of docosahexaenoic acid and genistein on COX-2, PGE2 and invasiveness in MDA-MB-231 breast cancer cells. Carcinogenesis 28, 809-815. doi: 10.1093/carcin/bgl183

Hsiao, Y. C., Peng, S. F., Lai, K. C., Liao, C. L., Huang, Y. P., Lin, C. C., et al. (2019). Genistein induces apoptosis in vitro and has antitumor activity against human leukemia HL-60 cancer cell xenograft growth in vivo. Environ. Toxicol. 34, 443-456. doi: 10.1002/tox.22698

Hwang, J. T., Lee, Y. K., Shin, J. I., and Park, O. J. (2009). Anti-inflammatory and anticarcinogenic effect of genistein alone or in combination with capsaicin in TPA-treated rat mammary glands or mammary cancer cell line. Ann. N. Y. Acad. Sci. 1171, 415-420. doi: 10.1111/j.1749-6632.2009.04696.x

Hwang, K. A., Park, M. A., Kang, N. H., Yi, B. R., Hyun, S. H., Jeung, E. B., et al. (2013). Anticancer effect of genistein on BG-1 ovarian cancer growth induced by $17 \beta$-estradiol or bisphenol A via the suppression of the crosstalk between estrogen receptor alpha and insulin-like growth factor-1 receptor signaling pathways. Toxicol. Appl. Pharmacol. 272, 637-646.

Ismail, I. A., Kang, K. S., Kim, J. W., and Sohn, Y. K. (2006). Genistein induces G2/M cell cycle arrest and apoptosis in rat neuroblastoma B35 cells; involvement of p21waf1/cip1, Bax and Bcl-2. Korea J. Pathol. 40, 39-347.

Jackson, I. L., Pavlovic, R., Alexander, A. A., Connors, C. Q., Newman, D., Mahmood, J., et al. (2019). BIO 300, a nanosuspension of genistein, mitigates radiation-induced erectile dysfunction and sensitizes human prostate cancer xenografts to radiation therapy. Int. J. Radiat. Oncol. Biol. Phys. 105, 400-409. doi: 10.1016/j.ijrobp.2019.05.062

Javanbakht, M. H., Sadria, R., Djalali, M., Derakhshanian, H., Hosseinzadeh, P., Zarei, M., Azizi, G., Sedaghat, R., and Mirshafiey, A. (2014). Soy protein and genistein improves renal antioxidant status in experimental nephrotic syndrome. Nefrologia $34,483-490$.

Jeong, J. W., Lee, H. H., Han, M. H., Kim, G. Y., Kim, W. J., and Choi, Y. H. (2014). Anti-inflammatory effects of genistein via suppression of the toll-like receptor 4-mediated signaling pathway in lipopolysaccharidestimulated BV2 microglia. Chem. Biol. Interact. 212, 30-39. doi: 10.1016/j. cbi.2014.01.012

Ji, G., Zhang, Y., Yang, Q., Cheng, S., Hao, J., Zhao, X., et al. (2012). Genistein suppresses LPS-induced inflammatory response through inhibiting NF-kappaB following AMP kinase activation in RAW 264.7 macrophages. PloS One 7, e53101. doi: 10.1371/journal.pone.0053101

Jiang, H., Fan, J., Cheng, L., Hu, P. and Liu, R. (2018). The anticancer activity of genistein is increased in estrogen receptor beta 1-positive breast cancer cells. OncoTargets and therapy 11, 8153 .

Kang, S., Kim, B. R., Kang, M. H., Kim, D. Y., Lee, D. H., Oh, S. C., et al. (2018). Anti-metastatic effect of metformin via repression of interleukin 6-induced epithelial-mesenchymal transition in human colon cancer cells. PloS One 13, e0205449. doi: 10.1371/journal.pone.0205449

Khaw, A. K., Yong, J. W. Y., Kalthur, G., and Hande, M. P. (2012). Genistein induces growth arrest and suppresses telomerase activity in brain tumor cells. Genes Chromosomes Canc. 51, 961-974.

Kim, S. H., Kim, C. W., Jeon, S. Y., Go, R. E., Hwang, K. A., and Choi, K. C. (2014). Chemopreventive and chemotherapeutic effects of genistein, a soy isoflavone, upon cancer development and progression in preclinical animal models. Lab. Anim. Res. 30, 143-150. doi: 10.5625/lar.2014.30.4.143

Lazarevic, B., Boezelijn, G., Diep, L. M., Kvernrod, K., Ogren, O., Ramberg, H., et al. (2011). Efficacy and safety of short-term genistein intervention in patients with localized prostate cancer prior to radical prostatectomy: a randomized, placebo-controlled, double-blind Phase 2 clinical trial. Nutr. Cancer 63, 889898. doi: 10.1080/01635581.2011.582221

Lee, D. H., Kim, M. J., Ahn, J., Lee, S. H., Lee, H., Kim, J. H., et al. (2017). Nutrikinetics of isoflavone metabolites after fermented soybean product (cheonggukjang) ingestion in ovariectomized mice. Mol. Nutr. Food Res. 61, 1700322-1700332. doi: 10.1002/mnfr.201700322

Lee, S. R., Kwon, S. W., Lee, Y. H., Kaya, P., Kim, J. M., Ahn, C., et al. (2019). Dietary intake of genistein suppresses hepatocellular carcinoma through AMPK-mediated apoptosis and anti-inflammation. BMC Cancer 19, 6. doi: $10.1186 / \mathrm{s} 12885-018-5222-8$ 
Li, J., Yue, Y., Hu, Y., Cheng, W., Liu, R., Pan, X., et al. (2014). Genistein suppresses tumor necrosis factor alpha-induced inflammation via modulating reactive oxygen species/Akt/nuclear factor kappaB and adenosine monophosphateactivated protein kinase signal pathways in human synoviocyte MH7A cells. Drug Des. Devel. Ther. 8, 315-323. doi: 10.2147/DDDT.S52354

Li, S., Li, J., Dai, W., Zhang, Q., Feng, J., Wu, L., et al. (2017). Genistein suppresses aerobic glycolysis and induces hepatocellular carcinoma cell death. Br. J. Cancer 117, 1518-1528. doi: 10.1038/bjc.2017.323

Li, Z., Li, J., Mo, B., Hu, C., Liu, H., Qi, H., et al. (2008). Genistein induces G2/M cell cycle arrest via stable activation of ERK1/2 pathway in MDA-MB-231 breast cancer cells. Cell Biol. Toxicol. 24, 401-409. doi: 10.1007/s10565-008-9054-1

Li, Y., Meeran, S. M., Patel, S. N., Chen, H., Hardy, T. M., and Tollefsbol, T. O. (2013). Epigenetic reactivation of estrogen receptor- $\alpha(\mathrm{ER} \alpha)$ by genistein enhances hormonal therapy sensitivity in ERa-negative breast cancer. Mol. Cancer 12, 9.

Liang, Y. S., Qi, W. T., Guo, W., Wang, C. L., Hu, Z. B., and Li, A. K. (2018). Genistein and daidzein induce apoptosis of colon cancer cells by inhibiting the accumulation of lipid droplets. Food Nutr. Res. 62. doi: 10.29219/fnr.v62.1384

Liberati, A., Altman, D. G., Tetzlaff, J., Mulrow, C., Gøtzsche, P. C., Ioannidis, J. P., et al. (2009). The PRISMA statement for reporting systematic reviews and meta-analyses of studies that evaluate health care interventions: explanation and elaboration. PloS Med. 6, e1000100. doi: 10.1371/journal.pmed.1000100

Lin, H.-M., Moon, B.-K., Yu, F., and Kim, H.-R. C. (2000). Galectin-3 mediates genistein-induced G2/M arrest and inhibits apoptosis. Carcinogenesis 21, 1941-1945. doi: 10.1093/carcin/21.11.1941

Liu, H., and Yu, G. Y. (2004). [Antimetastatic effects of genistein on salivary adenoid cystic carcinoma in vivo]. Zhonghua Kou Qiang Yi Xue Za Zhi 39, 373-375.

Liu, Y. N., Yin, J. J., Abou-Kheir, W., Hynes, P. G., Casey, O. M., Fang, L., et al. (2013). MiR-1 and miR-200 inhibit EMT via Slug-dependent and tumorigenesis via Slug-independent mechanisms. Oncogene 32, 296-306. doi: 10.1038/ onc. 2012.58

Lohr, J. M., Karimi, M., Omazic, B., Kartalis, N., Verbeke, C. S., Berkenstam, A., et al. (2016). A phase I dose escalation trial of AXP107-11, a novel multicomponent crystalline form of genistein, in combination with gemcitabine in chemotherapy-naive patients with unresectable pancreatic cancer. Pancreatology 16, 640-645. doi: 10.1016/j.pan.2016.05.002

Lu, C., Wang, Y., Xu, T., Li, Q., Wang, D., Zhang, L., Fan, B., Wang, F., et al. (2018). Genistein ameliorates scopolamine-induced amnesia in mice through the regulation of the cholinergic neurotransmission, antioxidant system and the ERK/CREB/BDNF signaling. Front. Pharmacol. 9, 1153.

Luo, Y., Wang, S.-X., Zhou, Z.-Q., Wang, Z., Zhang, Y.-G., Zhang, Y., et al. (2014). Apoptotic effect of genistein on human colon cancer cells via inhibiting the nuclear factor-kappa B (NF-кB) pathway. Tumor Biol. 35, 11483-11488. doi: 10.1007/s13277-014-2487-7

Lynch, S. M., O’neill, K. M., Mckenna, M. M., Walsh, C. P., and Mckenna, D. J. (2016). Regulation of miR-200c and miR-141 by methylation in prostate cancer. Prostate 76, 1146-1159. doi: 10.1002/pros.23201

Ma, C. H., Zhang, Y. X., Tang, L. H., Yang, X. J., Cui, W. M., Han, C. C., et al. (2018). MicroRNA-1469, a p53-responsive microRNA promotes Genistein induced apoptosis by targeting Mcl1 in human laryngeal cancer cells. BioMed. Pharmacother. 106, 665-671. doi: 10.1016/j.biopha.2018.07.005

Ma, J., Cheng, L., Liu, H., Zhang, J., Shi, Y., Zeng, F., et al. (2013). Genistein downregulates miR-223 expression in pancreatic cancer cells. Curr. Drug Targets 14, 1150-1156. doi: 10.2174/13894501113149990187

Macfarlane, L. A., and Murphy, P. R. (2010). MicroRNA: biogenesis, function and role in cancer. Curr. Genomics 11, 537-561. doi: 10.2174/ 138920210793175895

Matsukawa, Y., Marui, N., Sakai, T., Satomi, Y., Yoshida, M., Matsumoto, K., et al. (1993). Genistein arrests cell cycle progression at G2-M. Cancer Res. 53, 1328-1331.

Mazumder, M.a.R., and Hongsprabhas, P. (2016). Genistein as antioxidant and antibrowning agents in in vivo and in vitro: a review. Biomed. Pharmacother. 82, 379-392. doi: 10.1016/j.biopha.2016.05.023

Messing, E., Gee, J. R., Saltzstein, D. R., Kim, K., Disant'agnese, A., Kolesar, J., et al. (2012). A phase 2 cancer chemoprevention biomarker trial of isoflavone G-2535 (genistein) in presurgical bladder cancer patients. Cancer Prev. Res. (Phila) 5, 621-630. doi: 10.1158/1940-6207.CAPR-11-0455

Miao, Z. Y., Xia, X., Che, L., and Song, Y. T. (2018). Genistein attenuates brain damage induced by transient cerebral ischemia through up-regulation of Nrf2 expression in ovariectomized rats. Neurol. Res. 40, 689-695. doi: 10.1080/01616412.2018.1462879

Miekus, K., and Madeja, Z. (2007). Genistein inhibits the contact-stimulated migration of prostate cancer cells. Cell Mol. Biol. Lett. 12, 348-361. doi: 10.2478/s11658-007-0007-0

Mizushina, Y., Shiomi, K., Kuriyama, I., Takahashi, Y., and Yoshida, H. (2013). Inhibitory effects of a major soy isoflavone, genistein, on human DNA topoisomerase II activity and cancer cell proliferation. Int. J. Oncol. 43, 1117-1124.

Mongroo, P. S., and Rustgi, A. K. (2010). The role of the miR-200 family in epithelialmesenchymal transition. Cancer Biol. Ther. 10, 219-222. doi: 10.4161/cbt.10.3.12548

Moskot, M., Gabig-Ciminska, M., Jakobkiewicz-Banecka, J., Wesierska, M., Bochenska, K., and Wegrzyn, G. (2016). Cell cycle is disturbed in mucopolysaccharidosis type II fibroblasts, and can be improved by genistein. Gene 585, 100-103. doi: 10.1016/j.gene.2016.03.029

Myoung, H., Hong, S. P., Yun, P. Y., Lee, J. H., and Kim, M. J. (2003). Anti-cancer effect of genistein in oral squamous cell carcinoma with respect to angiogenesis and in vitro invasion. Cancer Sci. 94, 215-220. doi: 10.1111/j.1349-7006.2003.tb01422.x

Nazim, U. M., and Park, S. Y. (2015). Genistein enhances TRAIL-induced cancer cell death via inactivation of autophagic flux. Oncol. Rep. 34, 2692-2698.

Noori-Daloii, M. (2012). Study of antimetastatic effect of genistein through inhibition of expression of matrix metalloproteinase in A-549 cell line. J. Sci. Islam. Repub. Iran 23, 115-122.

Ouyang, G., Yao, L., Ruan, K., Song, G., Mao, Y., and Bao, S. (2009). Genistein induces G2/M cell cycle arrest and apoptosis of human ovarian cancer cells via activation of DNA damage checkpoint pathways. Cell Biol. Int. 33, 1237-1244. doi: 10.1016/j.cellbi.2009.08.011

Ozturk, S., Alp, E., Yar Saglam, A., Konac, E., and Menevse, E. (2018). The effects of thymoquinone and genistein treatment on telomerase activity, apoptosis, angiogenesis, and survival in thyroid cancer cell lines. J. Cancer Res. Ther. 14, 328-334.

Park, C. E., Yun, H., Lee, E. B., Min, B. I., Bae, H., Choe, W., et al. (2010). The antioxidant effects of genistein are associated with AMP-activated protein kinase activation and PTEN induction in prostate cancer cells. J. Med. Food 13, 815-820. doi: 10.1089/jmf.2009.1359

Perkin, A. G., and Newbury, F. G. (1899). LXXIX.-The colouring matters contained in dyer's broom (Genista tinctoria) and heather (Calluna vulgaris). J. Chem. Soc. Trans. 75, 830-839. doi: 10.1039/CT8997500830

Pintova, S., Dharmupari, S., Moshier, E., Zubizarreta, N., Ang, C., and Holcombe, R. F. (2019). Genistein combined with FOLFOX or FOLFOX-Bevacizumab for the treatment of metastatic colorectal cancer: phase I/II pilot study. Cancer Chemother. Pharmacol. 84, 591-598. doi: 10.1007/s00280-019-03886-3

Pool, H., Campos-Vega, R., Herrera-Hernandez, M. G., Garcia-Solis, P., GarciaGasca, T., Sanchez, I. C., et al. (2018). Development of genistein-PEGylated silica hybrid nanomaterials with enhanced antioxidant and antiproliferative properties o HT29 human colon cancer cells. Am. J. Transl. Res. 10, 2306-2323.

Rajaei, S., Alihemmati Ph, D. A., and Abedelahi Ph, D. A. (2019). Antioxidant effect of genistein on ovarian tissue morphology, oxidant and antioxidant activity in rats with induced polycystic ovary syndrome. Int. J. Reprod. Biomed. (Yazd) 17.

Rayalam, S., Della-Fera, M. A., Yang, J. Y., Park, H. J., Ambati, S., and Baile, C. A. (2007). Resveratrol potentiates genistein's antiadipogenic and proapoptotic effects in 3T3-L1 adipocytes. J. Nutr. 137, 2668-2673. doi: 10.1093/ jn/137.12.2668

Record, I. R., Dreosti, I. E., and Mcinerney, J. K. (1995). The antioxidant activity of genistein in vitro. J. Nutr. Biochem. 6, 481-485. doi: 10.1016/0955-2863(95)00076-C

Ronis, M. J. (2016). Effects of soy containing diet and isoflavones on cytochrome P450 enzyme expression and activity. Drug Metab. Rev. 48, 331-341. doi: 10.1080/03602532.2016.1206562

Russo, M., Russo, G. L., Daglia, M., Kasi, P. D., Ravi, S., Nabavi, S. F., et al. (2016). Understanding genistein in cancer: The "good" and the "bad" effects: a review. Food Chem. 196, 589-600. doi: 10.1016/j.foodchem.2015.09.085

Sahin, K., Yenice, E., Bilir, B., Orhan, C., Tuzcu, M., Sahin, N., et al. (2019). Genistein Prevents Development of Spontaneous Ovarian Cancer and Inhibits Tumor Growth in Hen Model. Cancer Prev. Res. 12, 135-146.

Sak, K. (2017a). Current epidemiological knowledge about the role of flavonoids in prostate carcinogenesis. Exp. Oncol. 39, 98-105. doi: 10.31768/2312-8852.2017.39(2):98-105

Sak, K. (2017b). Epidemiological evidences on dietary flavonoids and breast cancer risk: a narrative review. Asian Pac. J. Cancer Prev. 18, 2309-2328. 
Salahshoor, M. R., Mirzaei, F., Roshankhah, S., Jalili, P., and Jalili, C. (2019). Genistein improve nicotine toxicity on male mice pancreas. Anat. Cell Biol. 52, 183-190.

Sanaei, M., Kavoosi, F., Pourahmadi, M., and Moosavi, S. N. (2017). Effect of genistein and 17-beta estradiol on the viability and apoptosis of human hepatocellular carcinoma HepG2 cell line. Adv. BioMed. Res. 6, 163. doi: 10.4103/ abr.abr_53_17

Sanaei, M., Kavoosi, F., Valiani, A., and Ghobadifar, M. A. (2018). Effect of genistein on apoptosis and proliferation of hepatocellular carcinoma Hepa1-6 cell line. Int. J. Prev. Med. 9, 12. doi: 10.4103/ijpvm.IJPVM_249_16

Sathyapalan, T., Aye, M., Rigby, A. S., Fraser, W. D., Thatcher, N. J., Kilpatrick, E. S., et al. (2017a). Soy reduces bone turnover markers in women during early menopause: a randomized controlled trial. J. Bone Miner. Res. 32, 157-164. doi: 10.1002/jbmr.2927

Sathyapalan, T., Rigby, A. S., Bhasin, S., Thatcher, N. J., Kilpatrick, E. S., and Atkin, S. L. (2017b). Effect of soy in men with Type 2 Diabetes Mellitus and subclinical hypogonadism: a randomized controlled study. J. Clin. Endocrinol. Metab. 102, 425-433. doi: 10.1210/jc.2016-2875

Schneider, L. S., Hernandez, G., Zhao, L., Franke, A. A., Chen, Y. L., Pawluczyk, S., et al. (2019). Safety and feasibility of estrogen receptor-beta targeted phytoSERM formulation for menopausal symptoms: phase $1 \mathrm{~b} / 2 \mathrm{a}$ randomized clinical trial. Menopause 26, 874-884. doi: 10.1097/GME.0000000000001325

Shafiee, G., Saidijam, M., Tavilani, H., Ghasemkhani, N., and Khodadadi, I. (2016). Genistein induces apoptosis and inhibits proliferation of HT29 colon cancer cells. Int. J. Mol. Cell Med. 5, 178-191.

Shaji, D. (2018). Molecular docking studies of human MCT8 protein with soy isoflavones in Allan-Herndon-Dudley syndrome (AHDS). J. Pharm. Anal. 8, 318-323. doi: 10.1016/j.jpha.2018.07.001

Shanmugam, M. K., Lee, J. H., Chai, E. Z., Kanchi, M. M., Kar, S., Arfuso, F., et al. (2016). Cancer prevention and therapy through the modulation of transcription factors by bioactive natural compounds. Semin. Cancer Biol. 41, 35-47. doi: 10.1016/j.semcancer.2016.03.005

Shin, S. B., Woo, S. U., Chin, Y. W., Jang, Y. J., and Yim, H. (2017). Sensitivity of TP53-mutated cancer cells to the phytoestrogen genistein is associated with direct inhibition of Plk1 activity. J. Cell Physiol. 232, 2818-2828.

Shin, S. B., Woo, S. U., and Yim, H. (2019). Cotargeting Plk1 and androgen receptor enhances the therapeutic sensitivity of paclitaxel-resistant prostate cancer. Ther. Adv. Med. Oncol. 11, 1758835919846375. doi: 10.1177/1758835919846375

Song, M., Tian, X., Lu, M., Zhang, X., Ma, K., Lv, Z., et al. (2015). Genistein exerts growth inhibition on human osteosarcoma MG-63 cells via PPARgamma pathway. Int. J. Oncol. 46, 1131-1140. doi: 10.3892/ijo.2015.2829

Spagnuolo, C., Russo, G. L., Orhan, I. E., Habtemariam, S., Daglia, M., Sureda, A., et al. (2015). Genistein and cancer: current status, challenges, and future directions. Adv. Nutr. 6, 408-419. doi: 10.3945/an.114.008052

Su, S. J., Yeh, T. M., Chuang, W. J., Ho, C. L., Chang, K. L., Cheng, H. L., et al. (2005). The novel targets for anti-angiogenesis of genistein on human cancer cells. Biochem. Pharmacol. 69, 307-318. doi: 10.1016/j.bcp.2004.09.025

Sundaram, M. K., Ansari, M. Z., Al Mutery, A., Ashraf, M., Nasab, R., Rai, S., et al. (2018). Genistein induces alterations of epigenetic modulatory signatures in human cervical cancer cells. Anti-Cancer Agents in Medicinal Chemistry (Formerly Current Medicinal Chemistry-Anti-Cancer Agents), 18, 412-421.

Sung, M. J., Kim, D. H., Davaatseren, M., Hur, H. J., Kim, W., Jung, Y. J., et al. (2010). Genistein suppression of TNF- $\alpha$-induced fractalkine expression in endothelial cells. Cell Physiol Biochem. 26, 431-440.

Sutrisno, S., Aprina, H., Simanungkalit, H. M., Andriyani, A., Barlianto, W., Sujuti, H., et al. (2018). Genistein modulates the estrogen receptor and suppresses angiogenesis and inflammation in the murine model of peritoneal endometriosis. J. Tradit. Complement Med. 8, 278-281. doi: 10.1016/j.jtcme.2017.03.002

Suzuki, R., Kang, Y., Li, X., Roife, D., Zhang, R., and Fleming, J. B. (2014). Genistein potentiates the antitumor effect of 5-Fluorouracil by inducing apoptosis and autophagy in human pancreatic cancer cells. Anticancer Res. 34, 4685-4692.

Szeja, W., Grynkiewicz, G., and Rusin, A. (2017). Isoflavones, their Glycosides and Glycoconjugates. Synthesis Biol. Activity. Curr. Org. Chem. 21, 218-235. doi: 10. 2174/1385272820666160928120822

Tang, H., Wang, S., Li, X., Zou, T., Huang, X., Zhang, W., et al. (2019). Prospects of and limitations to the clinical applications of genistein. Discovery Med. 27, $177-188$.
Uifalean, A., Schneider, S., Ionescu, C., Lalk, M., and Iuga, C. A. (2015). Soy isoflavones and breast cancer cell lines: molecular mechanisms and future perspectives. Molecules 21, E13. doi: 10.3390/molecules21010013

Van Roosbroeck, K., and Calin, G. A. (2017). Cancer hallmarks and microRNAs: the therapeutic connection. Adv. Cancer Res. 135, 119-149. doi: 10.1016/ bs.acr.2017.06.002

Vanhees, K., Van Schooten, F. J., Van Waalwijk Van Doorn-Khosrovani, S. B., Van Helden, S., Munnia, A., Peluso, M., et al. (2013). Intrauterine exposure to flavonoids modifies antioxidant status at adulthood and decreases oxidative stress-induced DNA damage. Free Radic. Biol. Med. 57, 154-161. doi: 10.1016/j. freeradbiomed.2012.12.021

Wiegand, H., Wagner, A. E., Boesch-Saadatmandi, C., Kruse, H. P., Kulling, S., and Rimbach, G. (2009). Effect of dietary genistein on Phase II and antioxidant enzymes in rat liver. Cancer Genomics Proteomics 6, 85-92.

Xia, S., Wang, J., Kalionis, B., Zhang, W., and Zhao, Y. (2019). Genistein protects against acute pancreatitis via activation of an apoptotic pathway mediated through endoplasmic reticulum stress in rats. Biochem. Biophys. Res. Commun. 509, 421-428. doi: 10.1016/j.bbrc.2018.12.108

Xie, J., Wang, J., and Zhu, B. (2016). Genistein inhibits the proliferation of human multiple myeloma cells through suppression of nuclear factor-kappaB and upregulation of microRNA-29b. Mol. Med. Rep. 13, 1627-1632. doi: 10.3892/ mmr.2015.4740

Xie, Q., Bai, Q., Zou, L. Y., Zhang, Q. Y., Zhou, Y., Chang, H., et al. (2014). Genistein inhibits DNA methylation and increases expression of tumor suppressor genes in human breast cancer cells. Genes Chromosomes Canc. 53, 422-431.

Xie, X., Wang, S. S., Wong, T. C. S., and Fung, M. C. (2013). Genistein promotes cell death of ethanol-stressed HeLa cells through the continuation of apoptosis or secondary necrosis. Cancer Cell Int. 13, 63.

Yang, Y. M., Yang, Y., Dai, W. W., Li, X. M., Ma, J. Q., and Tang, L. P. (2016). Genistein-induced apoptosis is mediated by endoplasmic reticulum stress in cervical cancer cells. Eur. Rev. Med. Pharmacol. Sci. 20, 3292-3296.

Yazdani, Y., Rad, M. R. S., Taghipour, M., Chenari, N., Ghaderi, A., and Razmkhah, M. (2016). Genistein suppression of matrix metalloproteinase 2 (MMP-2) and vascular endothelial growth factor (VEGF) expression in mesenchymal stem cell like cells isolated from high and low grade gliomas. Asian Pac. J. Cancer Prev. 17, 5303.

Yeh, C. C., Fan, Y., Jiang, L., Yang, Y. L., He, B., You, L., and Mann, M. (2015). Genistein suppresses growth of human uterine sarcoma cell lines via multiple mechanisms. Anticancer Res. 35, 3167-3173.

Yu, X., Zhu, J., Mi, M., Chen, W., Pan, Q., and Wei, M. (2012). Anti-angiogenic genistein inhibits VEGF-induced endothelial cell activation by decreasing PTK activity and MAPK activation. Med. Oncol. 29, 349-357. doi: 10.1007/s12032-010-9770-2

Zhao, Q., Zhao, M., Parris, A. B., Xing, Y. and Yang, X. (2016). Genistein targets the cancerous inhibitor of PP2A to induce growth inhibition and apoptosis in breast cancer cells. Int. J. Oncol. 49, 1203-1210.

Zhang, H., Gordon, R., Li, W., Yang, X., Pattanayak, A., Fowler, G., et al. (2019). Genistein treatment duration effects biomarkers of cell motility in human prostate. PloS One 14, e0214078. doi: 10.1371/journal.pone.0214078

Zhang, Z., Wang, C. Z., Du, G. J., Qi, L. W., Calway, T., He, T. C., et al. (2013). Genistein induces $\mathrm{G} 2 / \mathrm{M}$ cell cycle arrest and apoptosis via ATM/p53dependent pathway in human colon cancer cells. Int. J. Oncol. 43, 289-296. doi: 10.3892/ijo.2013.1946

Conflict of Interest: KS is recruited by the company NGO Praeventio, Tartu, Estonia.

The remaining authors declare that the research was conducted in the absence of any commercial or financial relationships that could be construed as a potential conflict of interest.

Copyright $\odot 2019$ Tuli, Tuorkey, Thakral, Sak, Kumar, Sharma, Sharma, Jain, Aggarwal and Bishayee. This is an open-access article distributed under the terms of the Creative Commons Attribution License (CC BY). The use, distribution or reproduction in other forums is permitted, provided the original author(s) and the copyright owner(s) are credited and that the original publication in this journal is cited, in accordance with accepted academic practice. No use, distribution or reproduction is permitted which does not comply with these terms. 